\title{
O FILER CALCÁRIO NO CONCRETO: UMA REVISÃO
}

\section{ARTIGO DE REVISÃO}

ISAIA, Gustavo de Aguiar ${ }^{1}$

RIZZATTI, Eduardo ${ }^{2}$

ISAIA, Gustavo de Aguiar. RIZZATTI, Eduardo. O Filer Calcário no Concreto: Uma Revisão. Revista Científica Multidisciplinar Núcleo do Conhecimento. Ano 05, Ed. 12, Vol. 15, pp. 132-172. Dezembro de 2020. ISSN: 2448-0959, Link de acesso: https://www.nucleodoconhecimento.com.br/engenharia-civil/calcario-noconcreto

\section{RESUMO}

Devido à busca por benefícios técnicos, ambientais e econômicos, uma fração do cimento Portland (CP) é, cada vez mais, substituída por filer calcário $(\mathrm{FC})$, levantando uma questão sobre, até que ponto, este material pode impactar a qualidade do concreto. O retorno proporcionado pela substituição do FC no CP deve estar relacionado com o desempenho das estruturas de concreto em longo prazo. Sendo assim, vários são os questionamentos sobre quais os teores de FC que podem ser utilizados em substituição ao CP de modo a não impactar negativamente as estruturas de concreto. Desta maneira o presente trabalho tem por objetivo a realização de uma revisão de literatura sobre a influência dos diversos teores de FC nas características do concreto. $O$ trabalho pode auxiliar engenheiros e demais profissionais da área com informações técnicas sobre a interação do FC no concreto. Foram realizados levantamentos a respeito dos mais diversos teores de substituição de FC $(2,4 \%$ a

\footnotetext{
${ }^{1}$ Doutorando no Programa de Pós Graduação em Engenharia Civil da UFSM, Mestre em Patrimônio Cultural pela UFSM, Especialista em Patrimônio Cultural pela UFSM, Graduado em Engenharia Civil pela UFRGS.
}

2 Orientador. Doutorado em Engenharia Civil. 
$50 \%$ ), procurando verificar os efeitos físicos e químicos do material sobre a matriz cimentícia e seus reflexos sobre as propriedades do concreto no estado fresco e endurecido, bem como sua interação com a durabilidade. São apresentados, também, os benefícios ambientais advindos da utilização do FC e as perspectivas para a elaboração de concretos com altos teores de FC.

Palavras-chave: filer calcário, concreto, adições minerais, revisão.

\section{INTRODUÇÃO}

Do ponto de vista global, aconteceu um grande incremento na pesquisa e desenvolvimento em relação ao desempenho técnico do concreto, em especial, no que diz respeito à otimização da constituição da fase aglutinante. A evolução destas pesquisas, levou a uma otimização dos retornos econômicos e ambientais advindos da produção e consumo do concreto. Como recomendação geral tanto do ponto de vista econômico como ambiental, tem-se a incorporação de adições minerais (AM) no $\mathrm{CP}$, como benéficas, haja vista que elas são subprodutos de outros processos industriais. Do ponto de vista de disponibilidade as $A M$ mais comuns são a cinza volante (CV), a escória de alto forno (EAF) e a sílica ativa (SA). As AM densificam a microestrutura do concreto colaborando para uma diminuição da penetração de agentes agressivos, sua maior ou menor eficácia está relacionada com a composição química, características físicas e nível de substituição no CP. Com isso as AM são importantes atores no aumento da durabilidade do concreto.

Além das AM já citadas, o FC se destaca como um material que tem por característica sua incorporação no CP durante a fase de moagem, podendo ser adicionada, também, a posteriori conforme for o caso. Tendo em vista que as partículas de FC são, via de regra, menores que as do $\mathrm{CP}$, elas contribuem para uma melhora da reatividade da matriz cimentícia reduzindo os custos de energia, moagem e aumentando a dispersão dos grãos do CP no produto final.

O FC é a principal AM ao CP em teores baixos como nos CPs tipos CPI e CPV conforme as normas brasileiras, sendo usado, ainda, em substituição com a EAF 
(CPIII), CV (CPIV) ou nos cimentos compostos CPII-F (somente FC), CPII-Z (com CV) e CPII-E (com EAF), em teores mais elevados. Cada país ou região escolhe o tipo de substituição ao clínquer em função da sua disponibilidade local para evitar custos com o transporte, por serem resíduos ou subprodutos de baixo valor agregado.

O emprego do FC em substituição ao $\mathrm{CP}$ é mais adequado quando se objetiva alcançar menor grau de emanação de Gases de Efeito Estufa (GEE), por ser uma AM inerte. Por essa razão, em termos ambientais, o FC é mais utilizado junto com o clínquer nas fábricas de $\mathrm{CP}$, porque traz uma contribuição na diminuição da emanação total de $\mathrm{CO}_{2}$. Entretanto, a substituição do $\mathrm{CP}$ por $\mathrm{FC}$, em centrais de concreto, permite maiores alternativas de escolha quanto ao teor, em função das características locais, de equipamentos e materiais disponíveis, com um investimento relativamente baixo porque, na maioria dos casos, basta a adição de mais um silo de abastecimento na central dosadora.

O relatório do IEA (2009) mostra que a disponibilidade de EAF e CV, para suprir a produção de CP em 2050, superior a 5 bilhões de toneladas, representará menos de $20 \%$ da previsão da demanda por AM em substituição ao clínquer. O FC tem sido a solução mais utilizada para o equacionamento desse problema por apresentar grande disponibilidade, estando seu uso regulamentado pelas normas internacionais, por ser AM inerte que participa muito pouco nas reações de hidratação, não requerendo custos adicionais de energia. O seu efeito adverso é diminuir, proporcionalmente, o teor de ligante e, mesmo que o teor de água permaneça constante, promove um decréscimo na resistência mecânica que, atualmente, é resolvido pelas fábricas com a produção de CP com finura mais elevada.

O FC encontra-se sob a forma de: a) calcita, carbonato de cálcio, com moléculas arranjadas com geometria cristalina trigonal-romboédrica, b) dolomita, carbonato de cálcio e magnésio, com sistema predominante de cristais romboédricos; c) aragonita, carbonato de cálcio sob a forma de cristais ortorrômbicos metaestáveis. Os mais utilizados são os dois primeiros, sendo que, para uso como AM, estudos revelam que a calcita apresenta melhor desempenho, seguida da dolomita, nas características reológicas e propriedades mecânicas. 
As rochas calcárias são, entre as sedimentares, as mais abundantes na crosta terrestre, ocorrendo com mais frequência entre as latitudes $30^{\circ} \mathrm{N}$ e $30^{\circ} \mathrm{S}$, nas Américas, Europa, Índia, Rússia, Japão, entre outras regiões (WORLDATLAS, 2017). Sendo o FC o material carbonático obtido após moagem da rocha calcária. Segundo Bertolino et al. (2012) talvez não haja outras rochas com uma variedade de usos tão ampla quanto o calcário e o dolomito usados para a produção de: a) CP; b) cal para argamassas; c) produtos para a construção civil à base de fileres; d) concretos adensáveis, com fibras; e) pavimento de asfaltos; f) corretivo de solos, entre outras aplicações. Os maiores produtores mundiais de FC são a China, Índia e os Estados Unidos, com $75 \%$ da mineração mundial, a maioria sob a forma de FC (USGS, 2020).

Tendo em vista o exposto, ainda há uma grande disponibilidade para aumentar a incorporação do FC, em moagem conjunta, com o clínquer. Observa-se que existe um grande potencial para a incorporação do FC no CP porque a média mundial, de apenas $7 \%$, tem potencialidade para aumentar, dos atuais 5\%, como nos países em desenvolvimento, para até $35 \%$ na União Europeia. As AM ativas como EAF, CV, SA e outras, possuem média de uso no CP geralmente igual ou inferior à do $\mathrm{FC}$, porque não apresentam a mesma potencialidade de uso geral devido sua produção e disponibilidade mais restritas em alguns países ou regiões.

Existem algumas resistências, por parte do mercado consumidor ou de fabricantes, para aumento do teor de $\mathrm{FC}$ em substituição ao $\mathrm{CP}$, por questões de custos, desconhecimento tecnológico ou até sociocultural. À medida que se aumenta o teor de FC em substituição ao $\mathrm{CP}$, sem tomar as devidas providências técnicas, os produtos de hidratação decrescem e um cimento do tipo CP40 cai para o tipo CP32. Entretanto, existe a possibilidade, até um dado limite, de aumentar o teor de FC sem perda das propriedades físicas e mecânicas por meio de intermoagem conjunta por maior tempo, aumentando a finura e, assim, compensando a diminuição do aglutinante na mistura.

Também há a possibilidade de realizar a moagem separada do $\mathrm{FC}$, o que pode resultar em partículas mais finas que as do $\mathrm{CP}$, dependendo do tempo de moagem. Quando a substituição é em igualdade de massa, há um pequeno aumento no volume 
de pasta devido a maior massa específica do $\mathrm{CP}$, melhorando o seu comportamento reológico, o que permite reduzir, em parte, o fator a/ag e, por meio do efeito de nucleação, aumentar o teor de hidratação nas idades iniciais (JOHN et al., 2018). Esse comportamento pode acarretar benefícios ou pequena redução de desempenho, para teores de FC que não superem os $20 \%$ de substituição do CP (DE WEERDT, 2007).

De modo geral a literatura cita um nível de substituição entre 10\% e 20\% de FC em concretos, relatando que neste intervalo há um desempenho técnico adequado, muito semelhante com as características das misturas elaboradas somente com CP. É relatada uma melhora de eficiência do FC na fase de ligação, devido ao seu tamanho de partícula mais fino, a esta contribuição denomina-se "efeito filer". Entre os vários benefícios advindos deste efeito pode-se destacar: a redução na demanda de água, minoração da exsudação e, nos concretos endurecidos, o bloqueio dos poros capilares diminuindo a penetração de agentes agressivos (TSIVILIS, 2010).

Outra contribuição do FC ocorre na fase hidratação, tendo em vista que a sua finura, contribui para a aceleração das reações (TAYLOR, 1997). Esta contribuição resulta em uma melhora nos ganhos de resistência em idades precoces, podendo ocorrer o efeito contrário em idades posteriores. As partículas de FC podem, também, atuar como pontos de nucleação para a formação de C-S-H e participar da reação de hidratação por meio da formação de compostos como os (mono e hemi) carboaluminatos, que contribuem para um aumento na formação da etringita (LOTHBACH, et at., 2008).

\section{A REATIVIDADE DO FILER CALCÁRIO}

\subsection{0 “EFEITO FILER”}

A presença da AM na matriz cimentícia altera as características da microestrutura, dependendo do tipo, quantidade, tamanho e distribuição dos constituintes da fase sólida, além da estrutura dos poros. Sua influência se destaca, primordialmente, na zona de transição entre a pasta e os agregados, devido às modificações do conteúdo 
de sólidos nessa interface que apresenta, nos concretos convencionais, maior fator a/ag.

O FC, por ser praticamente inerte e geralmente possuir alta superfície específica, exerce pouca interferência direta sobre as reações de hidratação do CP, entretanto, apresenta papel muito importante na microestrutura da matriz cimentícia, por meio do efeito físico, especialmente quando moído conjuntamente nas fábricas de CP resultando em um aumento da sua finura. De acordo com Courard et al. (2018) o FC pode ser denominado de AM quando apresentar superfície específica maior que 400 $\mathrm{m}^{2} \cdot \mathrm{kg}^{-1}$.

Considera-se efeito físico quando a mera presença de material cimentício, ou mesmo de uma AM inerte, interfere nas reações de hidratação do CP por meio do potencial elétrico superficial (BERODIER; SCRIVENER, 2015; SCRIVENER et al., 2015). Segundo esses autores, este efeito apresenta dois componentes: a) o efeito diluição, para um mesmo fator a/ag, provocando mais espaços para a formação de compostos hidratados e, portanto, maior grau de hidratação do que nas misturas sem substituição; b) maior quantidade de locais de nucleação provocada pela maior superfície específica dos materiais cimentícios, para a formação dos compostos hidratados. Embora este segundo efeito seja menor que o primeiro, para AM muito finas como a SA, ocorre uma aceleração relevante na hidratação do $\mathrm{CP}$.

As ações físicas do FC, por meio dos efeitos diluição e nucleação interferem no tempo e reologia das pastas cimentícias. Sua interferência ocorre nas reações que regem a formação dos compostos hidratados como C-S-H, Portlandita e C-A-S-H, podendo apresentar velocidade e desprendimento de calor distintos, dependendo do teor, granulometria e composição do FC, em especial da presença de impurezas.

\subsection{O EFEITO DILUIÇÃO}

A incorporação do FC em sistemas contendo CP pode acarretar o efeito da diluição, trazendo consigo consequências negativas relacionadas com a durabilidade $\mathrm{e}$ resistência mecânica. Pode-se dizer que a diluição acontece por ocasião da 
substituição de partículas de um material mais reativo, por outras de menor reatividade e/ou inerte (IRASSAR, 2009). Esta diminuição do teor de CP acarreta um incremento no fator água/cimento efetivo (IRASSAR et al., 2015). Como consequência do efeito de diluição ocorre à diminuição dos produtos de hidratação, resultando na minoração da resistência à compressão do concreto em todas as idades. Com isso há uma redução das vantagens oriundas das contribuições de natureza física do FC por ocasião de substituições acima dos 5\% (AQEL; PANESAR, 2016). A substituição por FC abaixo de $5 \%$, via de regra, não causam diminuição no desempenho do concreto conforme Hawkins et al. (2003).

Dentro de certos limites o aumento da finura do clínquer pode compensar o efeito de diluição. Tendo em vista que o FC possui densidades que variam entre 2,6-2,7 g.cm${ }^{3}$, sua substituição, por ocasião de uma base de reposição em massa, contribui para o incremento do volume de pasta, bem como para a distância de separação entre partículas. Desta maneira poderiam ser explicadas, mesmo que parcialmente, a melhora no comportamento reológico do concreto, o que contribui para uma redução do fator a/ag dada uma trabalhabilidade constante, ajudando a compensar os efeitos da diluição (HAWKINS et al., 2003).

\subsection{O EFEITO “NUCLEAÇÃO HETEROGÊNEA"}

A hidratação dos grãos de CP ocorre pela dissolução gradativa das fases anidras que compõe o clínquer e o sulfato de cálcio (gipsita), seguida de uma precipitação dos hidratos sob as partículas, formando uma camada externa. A este mecanismo de hidratação dá-se o nome de dissolução/precipitação, o qual ocorre nos instantes iniciais da reação de hidratação dos grãos de CP. À medida que a reação de dissolução/precipitação ocorre há uma cobertura gradual dos grãos, impedindo gradativamente a dissolução das fases anidras. Neste intervalo o crescimento da taxa de reação se mantém constante, podendo ser observado um período de aceleração no calor de hidratação.

Após a consolidação da pasta inicia um segundo mecanismo denominado de topo químico, nele há uma difusão da água pela camada de hidratos que estava 
inicialmente precipitada. Desta maneira a água irá atingir a parte dos grãos de CP, ainda, anidra a fim de dar prosseguimento à hidratação. A transição do mecanismo de hidratação por dissolução/precipitação para topo químico ocorre em um momento de desaceleração das reações, podendo ser comprovado pelo ensaio do calor de hidratação (KADRI; DURVAL, 2002; TAYLOR, 1997). Com isso há uma diminuição na taxa de solubilização dos anidros, diminuindo o teor de íons e, portanto a precipitação dos compostos hidráulicos. Assim é possível dizer que a cobertura dos grãos anidros constitui-se no começo da reação topo química (KADRI; DURVAL, 2002).

Assim a incorporação do FC ao material cimentício constitui-se em um elemento que modifica a cinética das reações dos grãos de CP. A contribuição do FC ocorre pelo aumento do grau de hidratação (KADRI; DURVAL, 2002). Com isso a nucleação heterogênea ocorre pela presença do FC, e deve-se ao menor tamanho das partículas que, ao preencherem os vazios, tendem a aumentar a densidade da mistura, bem como contribuir para formação de pontos de nucleação para os produtos de hidratação. Desta forma o crescimento dos cristais ocorre não somente a partir da superfície dos grãos de CP, mas na superfície do FC, trazendo consigo um aumento nas reações e modificações na tipologia dos produtos de hidratação formados. A partir da diminuição dos espaços ocorre a formação de um grande número de cristais ao invés de um reduzido número de cristais de tamanho grande (HEMALATHA; SANTHANAM, 2018; MEHDIPOUR et al., 2017).

A nucleação heterogênea baseia-se em dois fatores principais: a) maior espaço para alojar a formação de produtos de hidratação advindos da troca dos grãos de CP por FC e que tem um tamanho menor de partícula (Figura 1); b) disponibilização da superfície dos grãos de FC como local onde há a precipitação e crescimento dos hidratos. 
Figura 1 - Esquema da distribuição de partículas em um sistema contendo 100\% de CP (a) e o sistema com $40 \%$ do CP substituído por uma AM (b)

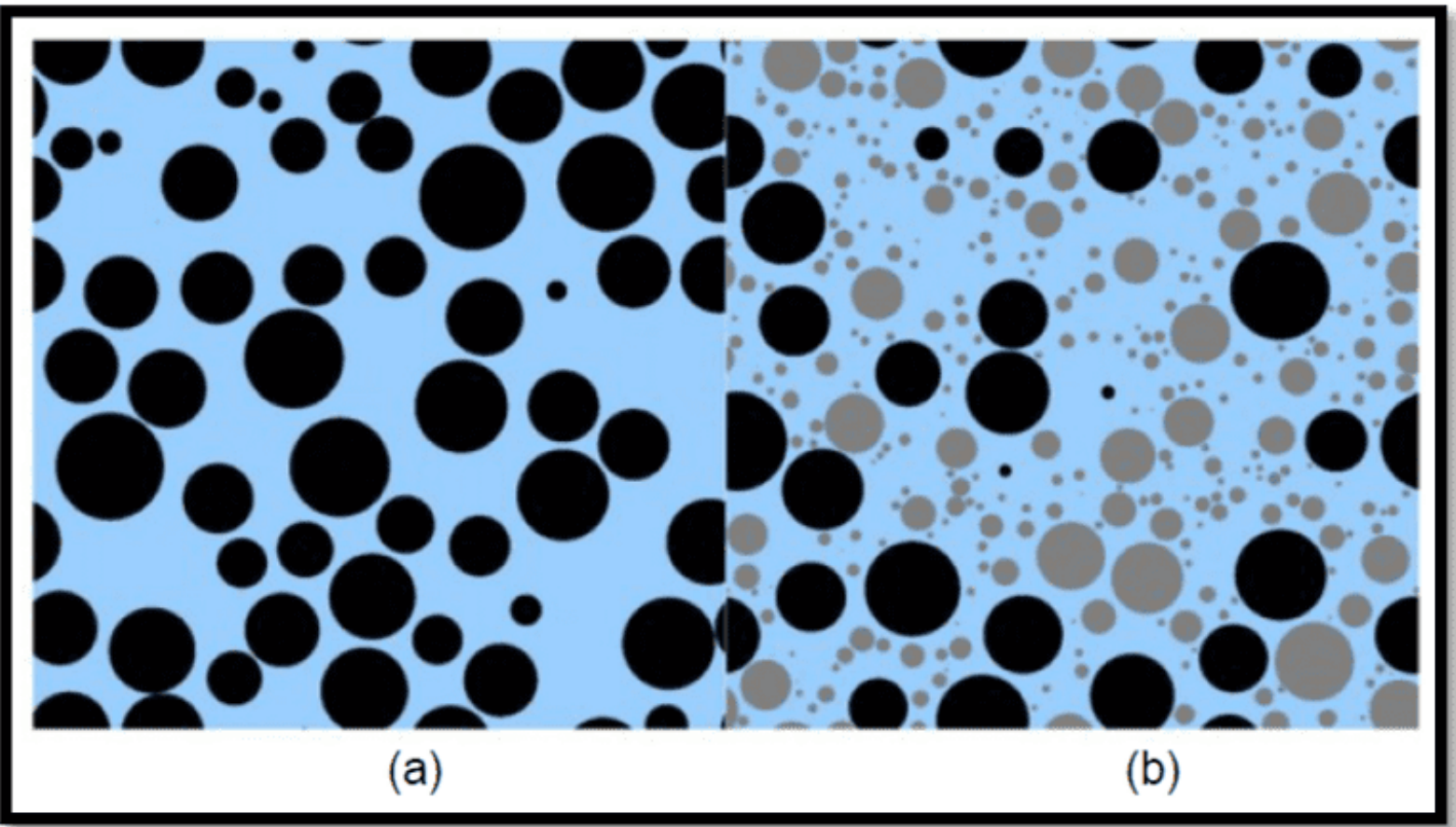

Fonte - Scrivener et al. (2015)

A nucleação heterogênea constitui-se em um processo basicamente físico que conduz a ativação química da hidratação do CP. De maneira geral ocorre pela precipitação dos hidratos sobre as partículas de $\mathrm{CP}$, catalisando assim o processo de hidratação (nucleação), pois reduz a barreira energética necessária para a ocorrência das reações (LAWRENCE et al., 2003).

O mecanismo da nucleação heterogênea, levantado por Lawrence et al. (2003) pode melhor ser visualizado na Figura 2. Devido a menor espessura da película formada ao redor dos grãos de CP anidro, tem-se facilitada a hidratação da camada subjacente (anidra). Desta forma, devido a uma menor espessura das partículas de FC, bem como a proximidade das mesmas com as partículas de CP, ocorrerá um aumento na taxa de hidratação.

A propositura de Lawrence et al. (2003), apesar de coerente, constitui-se em um modelo que simplifica o fenômeno, haja vista que não considera, entre outros 
aspectos, a maior ou menor afinidade entre os grãos de CP e as partículas de FC. Além do aspecto relacionado com afinidade química e cristalográfica entre os dois tipos de partículas, o modelo não considera a tensão superficial inicial gerada na interface dos grãos de CP que se relacionam com as características do meio aquoso como: a) densidade; b) $\mathrm{pH}$; c) teor de álcalis, entre outros.

Figura 2 - Representação esquemática da hipótese sobre a majoração da hidratação do CP nas primeiras idades. (a) Com AM inerte; (b) Sem AM inerte

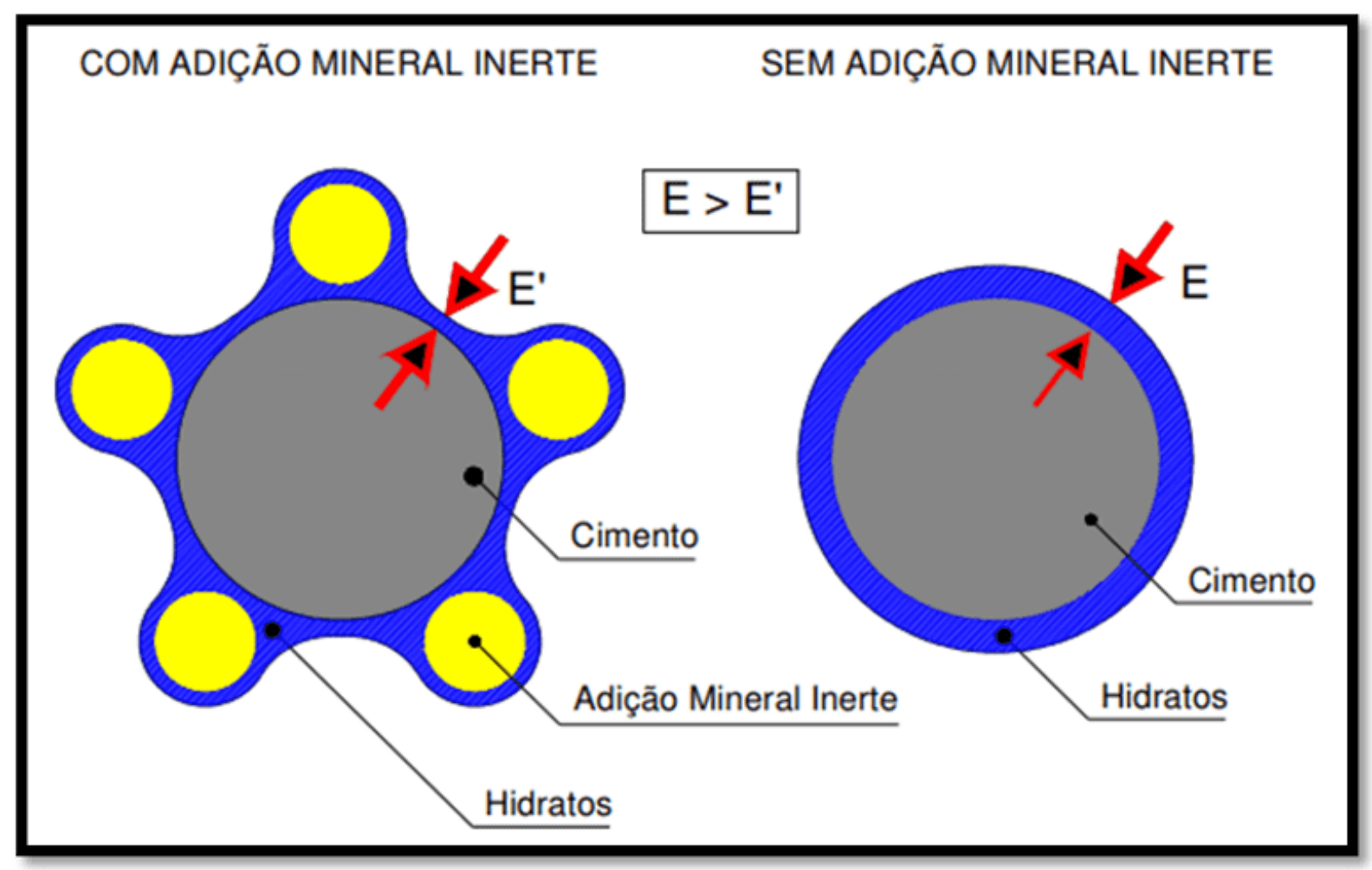

Fonte - Lawrence et al. (2003) 
Figura 3 - Hidratos formados devido à nucleação heterogênea

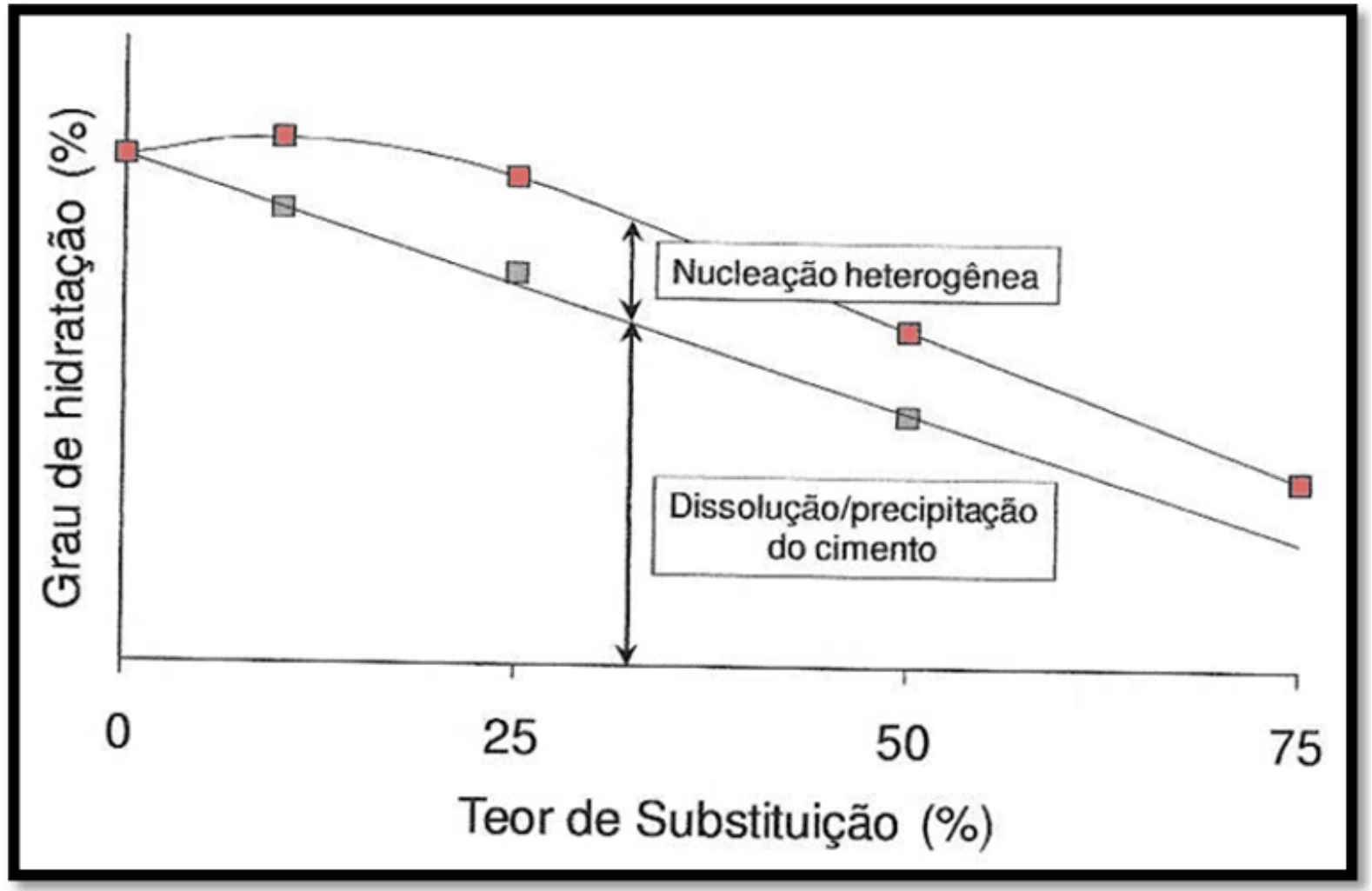

Fonte - Lawrence et al. (2003)

No trabalho de Lawrence et al. (2003) é possível observar as distintas contribuições relacionadas ao grau de hidratação tendo como premissa o teor de substituição do CP por FC. Desta forma é possível constatar o teor mais adequado de substituição para a obtenção da melhor eficiência afim de que a cinética de hidratação seja alcança em sua plenitude. Na Figura 3 pode-se constatar a tendência no incremento do grau de hidratação, a partir do teor de substituição do CP por FC, segundo os autores. Entre os $25 \%$ e $30 \%$ no teor de substituição é possível observar o incremento máximo no grau de hidratação. Neste caso deve-se salientar que a área específica BET do FC constitui-se na responsável por determinar a amplitude do incremento, assim sendo, quanto maior a finura do FC maior será o incremento no grau de hidratação (KADRI; DUVAL, 2002).

Ao analisar a Figura 3 constata-se que valores acima de 30\% implicam em uma diminuição do incremento marginal de hidratação. Com isso tem-se que a nucleação 
heterogênea pode levar a um aumento na resistência à compressão em idades iniciais, que pode ser semelhante e/ou maior em relação aos concretos sem a substituição de FC (KRISHNAN et al., 2018; MEDJIGBODO et al., 2018).

\subsection{O FILER CALCÁRIO E AS REAÇÕES DE HIDRATAÇÃO}

No caso do FC, diferente das pozolanas, o efeito químico não decorre da atividade pozolânica, mas sim pela interação entre o $\mathrm{FC}\left(\mathrm{CaCO}_{3}\right)$ e a alumina do $\mathrm{CP}$ presente, principalmente no $\mathrm{C}_{3} \mathrm{~A}$. Desta interação decorre a formação de uma nova fase denominada monocarboaluminato hidratado. Bonavetti et al. (2003) e Battagin e Battagin (2010) corroboram esta afirmação lembrando que apesar do FC ser um material que preponderantemente interage de maneira física com o CP, apresenta, também, certa reatividade química ao participar da reação para a formação de monocarboaluminatos ao substituir a gipsita. Bentz (2006) cita que a formação do monocarboaluminato, também denominado de fase AFmc, ocorre pela diminuição na formação do monosulfoaluminato (fase AFm) que é a fase normalmente formada na hidratação do CP.

Nos demais aspectos as reações de hidratação do CP ocorrem de maneira normal, ou seja, a hidratação dos silicatos para formação do C-S-H e da Portlandita. Contudo há uma aceleração na formação da etringita por ocasião da presença do FC, sendo que a formação da fase AFm (monosulfoaluminato) passa a ser adiada ou não ocorrer, tendo em vista a grande concentração de carbonato de cálcio presente no sistema cimentício (BONAVETTI et al., 2001). A cinética desta mudança em relação aos CPs sem adição ocorre em função da troca de alguns íons sulfato por íons carbonato quando da hidratação do $\mathrm{C}_{3} \mathrm{~A}$ conforme Vernet e Noworyta (1992).

As reações químicas mencionadas são descritas segundo a sequência de reações a seguir: a) formação de etringita por consumo do monosulfato; b) quando o monosulfato é exaurido forma-se monocarboaluminato pelo consumo do hemicarboaluminato; c) quando a fase hemicarboaluminato é esgotada por carbonato de cálcio adicional, não reage embora permaneça como uma fase estável. As reações a) e b) resultam em preenchimento dos poros e redução da porosidade, enquanto 
quantidades adicionais de carbonatos da reação aumentam a porosidade. CPs que possuem maior quantidade de $C_{3} A$ resultam na formação de mais monocarboaluminato, logo, possibilitando o consumo de maiores teores de carbonato de cálcio, antes de atingir o limite necessário para que este aumente a porosidade da pasta cimentícia (Figura 4) (COURARD et al., 2018).

Figura 4 - Sistema das fases hidratadas no subsistema ternário de $\mathrm{CaSO}_{4}-\mathrm{C}_{3} \mathrm{~A}$ $\mathrm{CaCO}_{3}$

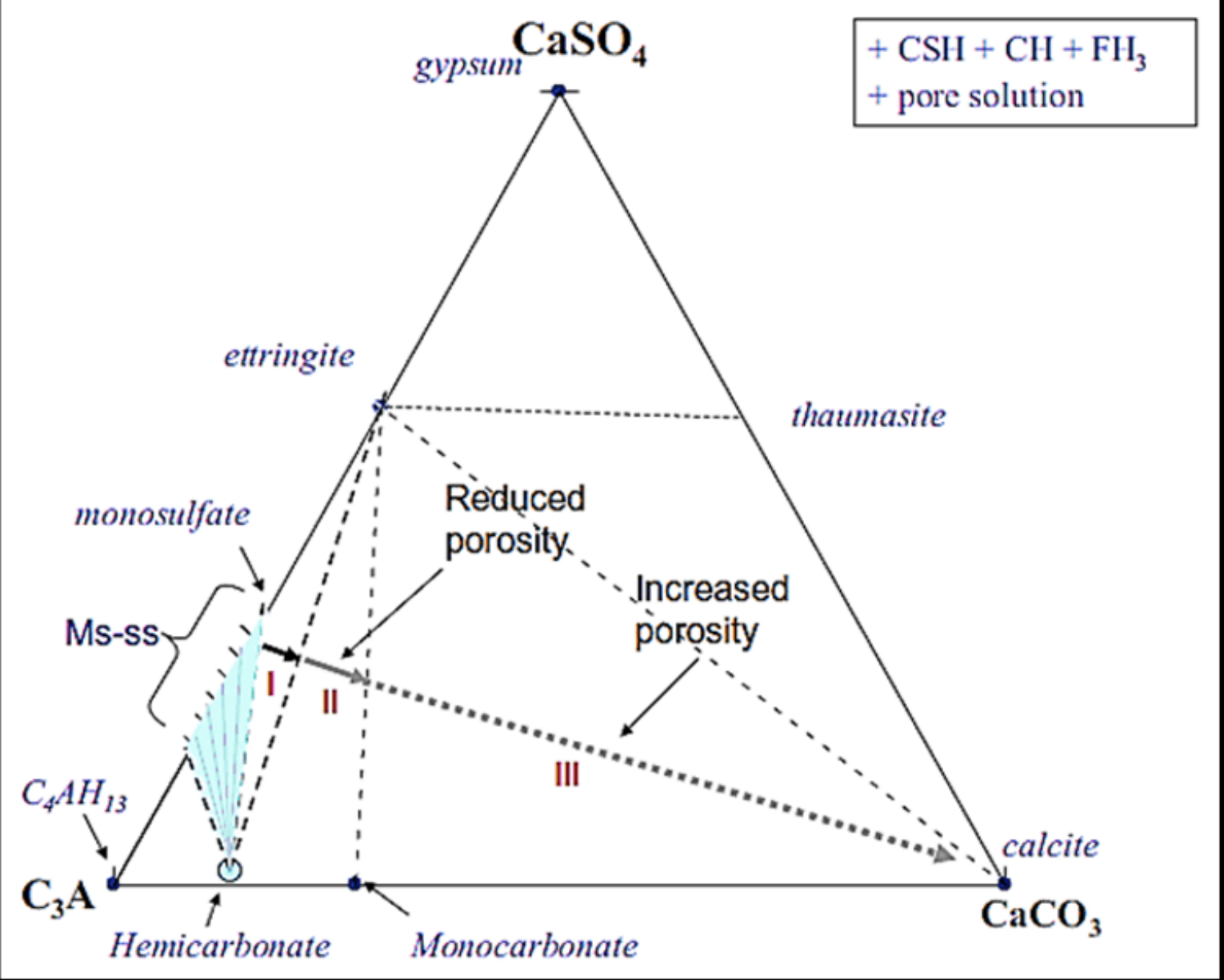

Fonte - Courard et al. (2018)

A Figura 4 mostra o que foi explanado por intermédio do sistema ternário $\mathrm{C}_{3} \mathrm{~A}-\mathrm{CaSO}_{4}-$ $\mathrm{CaCO}_{3}$ para o $\mathrm{CP}$ com $\mathrm{FC}$. As fases neste subsistema estão em itálico e as regiões de estabilidade estão indicadas pelas três fases nas quais a composição de qualquer 
sistema dado é plotado dentro do diagrama. As fases excedentes são mostradas externas ao diagrama acima à direita.

Tendo em vista um melhor entendimento sobre as mudanças decorrentes da incorporação do FC na cinética da hidratação, Bonavetti et al. (2001) realizaram um experimento que consistia na avaliação dos compostos em pastas de CP por um período de 90 dias. Foram confeccionadas duas pastas, a primeira sem FC e a segunda com $20 \%$ do material. As pastas foram avaliadas por meio do ensaio de difratometria de raios- $x$, sendo avaliada a evolução da hidratação das pastas conforme pode ser observado na Figura 5.

Figura 5 - Formação de compostos a partir da hidratação de CP com e sem adição de FC
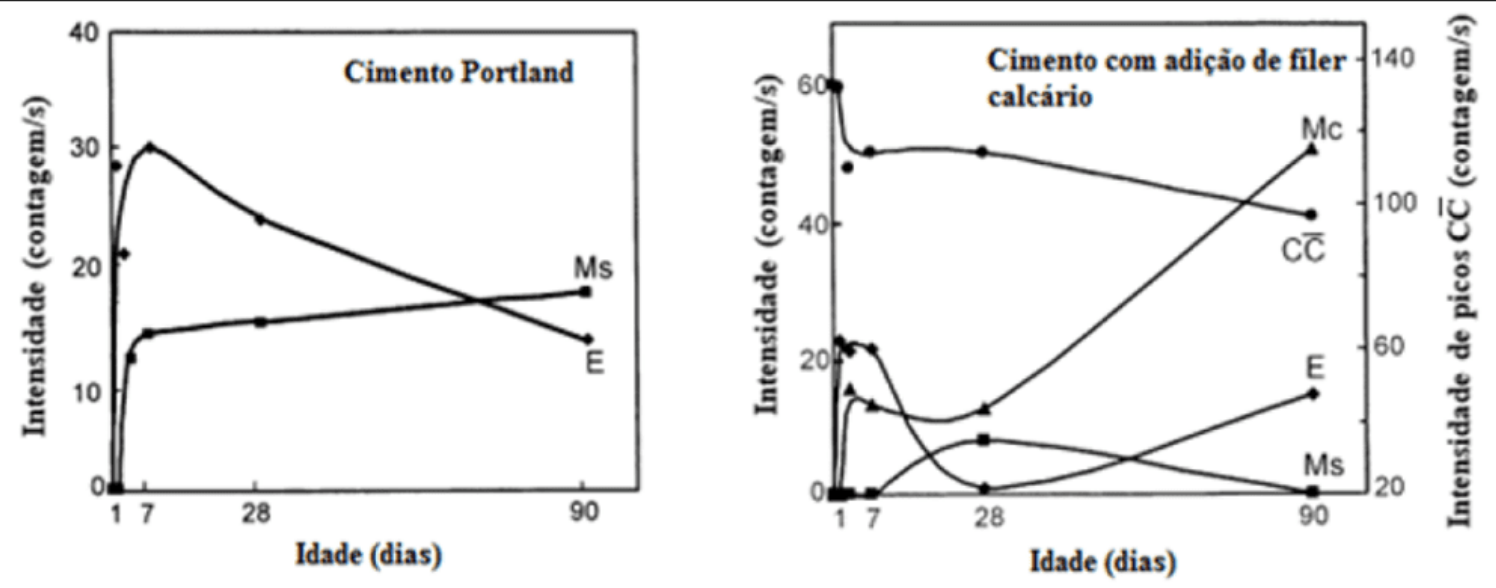

MS = monossulfoaluminato $; \mathrm{E}=$ etringita $; \mathrm{MC}=$ monocarboaluminato $; \mathrm{CC}=$ carbonato de cálcio

Fonte - Bonavetti et al. (2001)

Em relação à pasta sem incorporação de FC foram constatados os produtos normalmente encontrados na hidratação do $\mathrm{CP}$, ou seja, etringita e Portlandita oriundos da hidratação dos aluminatos e dos silicatos. Foi observada aos 3 dias a transformação da etringita em monosulfoaluminato, o qual teve um progressivo incremento na concentração até os 90 dias. Em relação à pasta com $20 \%$ de $\mathrm{FC}$, observou-se uma estabilidade da etringita até os 7 dias e, ato contínuo, a 
transformação em monosulfoaluminato ocorrendo de maneira tardia; sendo que o monocarboaluminato teve sua presença detectada já aos 3 dias de idade.

Contudo somente aos 28 dias de idade, houve um incremento substantivo na concentração de monocarboaluminato, o qual se deu, conjuntamente, por uma redução do monossulfoaluminato. Os autores explicam que o incremento na concentração do composto monocarboaluminato deve-se a maior disponibilidade de íons carbonato no sistema, sendo que os mesmos foram fornecidos pelo FC gerando, assim, a transformação de monosulfoaluminato em monocarboaluminato, tendo em vista que o segundo é mais estável que o primeiro. Com isso há uma reconversão do monosulfoaluminato em etringita, tendo em vista os íons sulfato liberados da decomposição do monosulfoaluminato (BONAVETTI et al., 2001).

$\mathrm{Na}$ mesma linha dos autores citados anteriormente, Lothenbach et al. (2008) realizaram uma avaliação semelhante. Neste caso foi avaliada a formação de novos compostos a partir da difração de raios- $x$, onde foram comparados um CP de referência denominado " $P C$ " (sem FC) e outro denominado " $P C 4$ " com incorporação de $4 \%$ de FC. Também nesta situação foi constatada a diminuição na concentração de monosulfoaluminato em detrimento do monocarboaluminato em virtude da presença de FC, conforme pode ser observado na Figura 6. 
Figura 6 - Difratometria de raios-X para avaliação dos compostos formados a partir da hidratação de CPs com e sem adição de FC

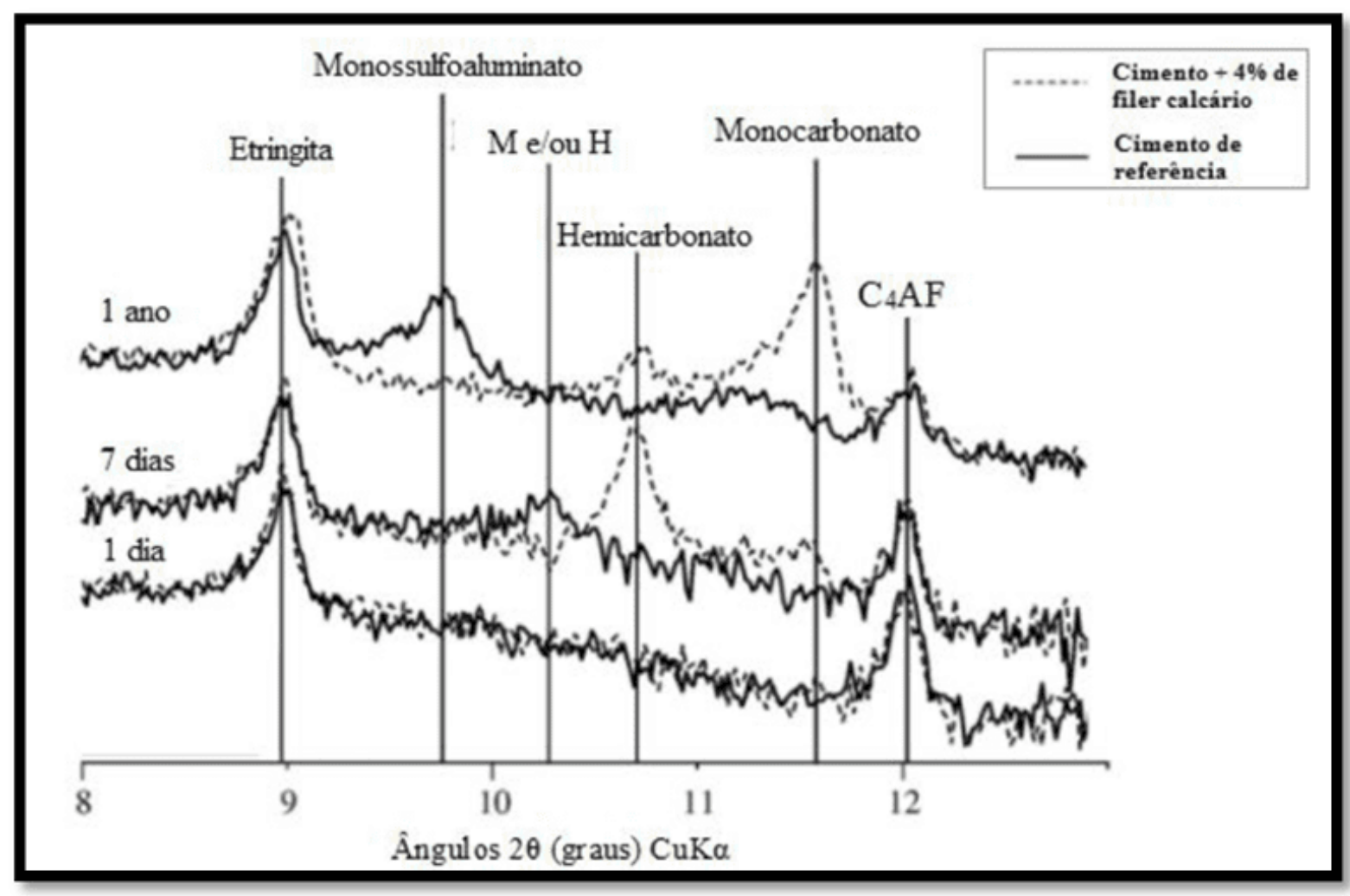

Fonte - Lothenbach et al. (2008)

Além da formação do monocarboaluminato, é possível observar a formação de outro composto denominado de hemicarboaluminato. Conforme Antoni (2013) o surgimento desta nova fase ocorre devido a uma reduzida concentração de $\mathrm{CaCO}_{3}$ no sistema. Contudo Ipavec et al. (2011), colocam que o composto possui a característica de se tornar instável na presença de elevadas concentrações de $\mathrm{CaCO}_{3}$, sendo possível constatar este composto em idades iniciais onde o teor de calcita é elevado, sendo que a posteriori ele é convertido em monocarboaluminato na medida em que areação de hidratação progride.

Pode-se dizer que as fases carboaluminato hidratado (mono e hemi) são devidas a fatores que se relacionam com a quantidade de alumina no sistema cimentício, bem como pela finura do material carbonático. É possível observar, neste tipo de sistema (com incorporação de $\mathrm{FC}$ ), que a quantidade de monocarboaluminato possui um viés 
de alta em todas as idades, isto ocorre devido ao elevado teor de alumina no CP (BARKER; CORY, 1991). Tanto Hawkins et al. (2003) como Stark et al. (1999), constataram que o potencial reativo do FC neste tipo de reação ocorreu em finuras mais elevadas.

No caso da contribuição química do $\mathrm{FC}$, as vantagens não se dão apenas pela formação de novos compostos hidratados como carboaluminatos (mono e hemi), todavia pelo incremento que é dado ao volume final dos produtos hidratados. Este incremento está relacionado com a estabilização da etringita a partir da formação do monocarboaluminato, gerando com isso uma majoração do volume total da fase hidrata e por consequência uma diminuição da porosidade do sistema (LOTHENBACH et al., 2008).

Contudo ao consultar-se a literatura sobre o assunto é possível constatar que certas discrepâncias vêm à tona, principalmente quanto à formação do hemicarboaluminato a partir do monocarboaluminato. Também é possível observar certas alterações de posicionamento em relação aos compostos formados, tendo em vista sua estabilidade quando se relaciona aspectos ligados com a temperatura. Neste sentido Taylor (1997) coloca que existe uma proporcionalidade entre as taxas de produção dos íons $\mathrm{SO}_{4}{ }^{2-}$, $\mathrm{Al}(\mathrm{OH})^{4-}$ e $\mathrm{CO}_{3}{ }^{2-}$ por ocasião da formação das fases $\mathrm{AFm}$ (monosulfato) e AFt (etringita). A colocação de Taylor (1997) encontrou eco nos estudos de Matschei et al. (2007), onde os autores propõem um modelo que tem por objetivo a definição da fase formada com base nas relações propostas inicialmente pelo próprio Taylor (1997), ou seja, os coeficientes entre $\mathrm{SO}_{4}{ }^{2-} / \mathrm{Al}_{2} \mathrm{O}_{3}$ e $\mathrm{CO}_{3}{ }^{2-} / \mathrm{Al}_{2} \mathrm{O}_{3}$. As conclusões de Matschei et al. (2007) sobre o cálculo das quantidades pode melhor ser observada no diagrama da Figura 7. 
Figura 7 - Diagrama para quantificação das fases produzidas pela adição de FC

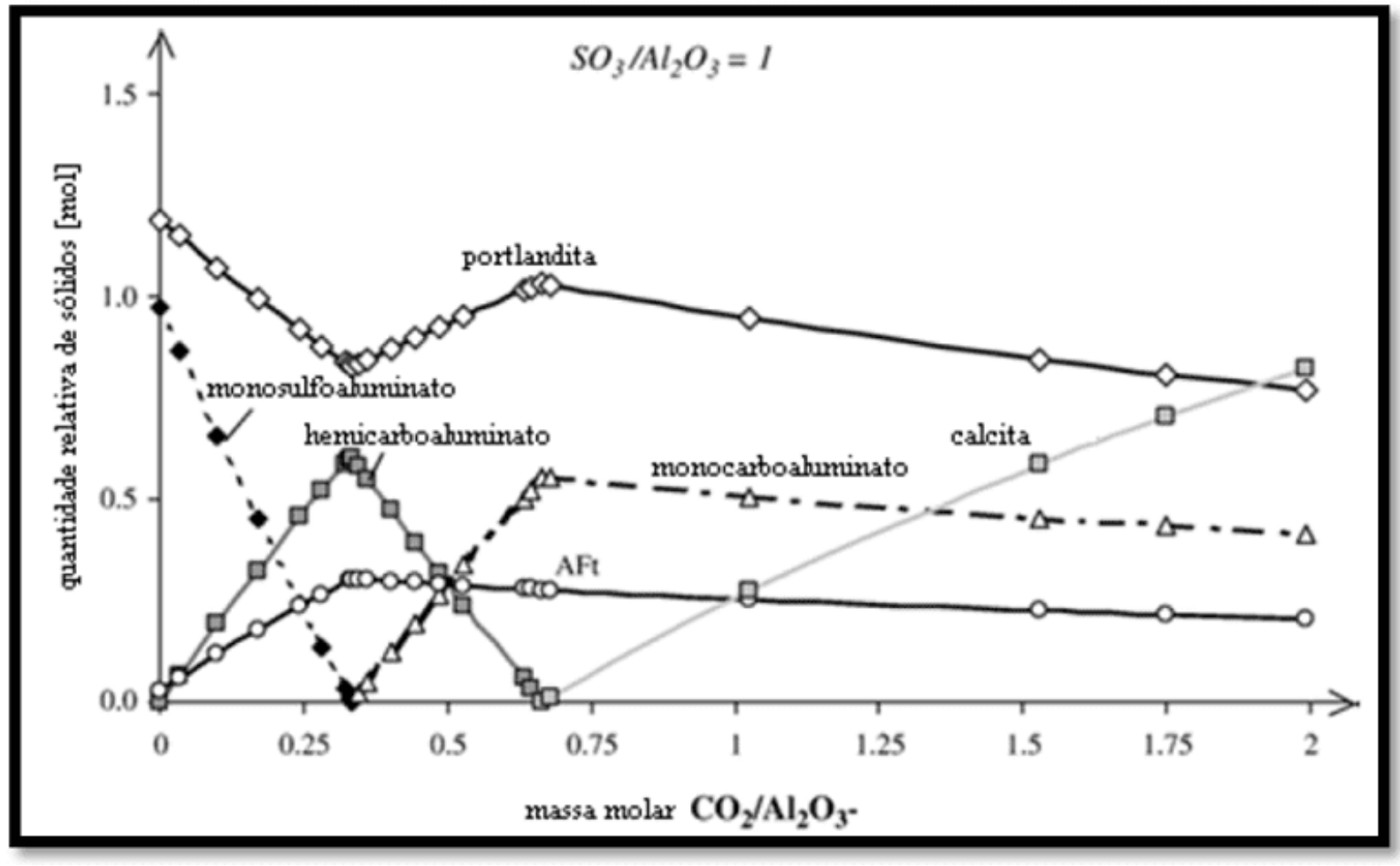

Fonte - Matschei et al. (2007)

É possível observar que pequenos incrementos na quantidade de FC conduzem a um rápido consumo do monosulfoaluminato, acarretando uma majoração na quantidade de hemicarboaluminato. Contudo devido ao gesso estar subsaturado, o sulfato liberado na dissolução do monosulfoaluninato não permanece em solução. Desta forma há a formação de etringita a partir dos íons sulfato que estão disponíveis no sistema. Assim pode-se dizer que há um câmbio entre os íons $\mathrm{SO}_{4}{ }^{2-} e \mathrm{CO}_{3}{ }^{2-}$, onde ocorre a liberação dos primeiros para a produção de etringita. A reação descrita implica no consumo de Portlandita e alumina acarretando uma diminuição na concentração de Portlandita (MATSCHEl et al., 2007).

\subsection{O FILER CALCÁRIO E A GRANULOMETRIA}

Com relação à reatividade do $\mathrm{FC}$ é importante levar em conta o papel da granulometria e da superfície BET. Estudos de Espining (2008) apontam para o papel de destaque desta característica física do FC nos concretos, cujas principais conclusões foram: a) 
a natureza física do melhor empacotamento, pela incorporação de FC, não só irá governar a fluidez do concreto, mas também a resistência à compressão devido à matriz mais densa e melhor dispersão dos grãos de CP; b) o efeito da nucleação heterogênea na resistência à compressão depende da afinidade do FC com os hidratos de CP, e aumenta com a finura e a área superficial específica; c) o FC com maior área BET tende a diminuir a fluidez do concreto, aumentando a retração autógena, diminuindo a evaporação e, consequentemente, diminuindo a tendência à fissuração plástica o que propicia uma maior resistência à compressão; d) para um aumento na área BET da ordem de $1.000 \mathrm{~m}^{2} . \mathrm{kg}^{-1}$, implica na necessidade de inclusão de água adicional na ordem de 0,8\%, em massa, para que a trabalhabilidade seja mantida; e) para um aumento de $1.000 \mathrm{~m}^{2} . \mathrm{kg}^{-1}$ na área BET, resulta em uma diminuição de $20 \%$ na retração plástica; f) a inclusão de água a fim de compensar um aumento da área BET (item b), traz um aumento na fissuração e uma diminuição na resistência.

Pode-se dizer que existe uma correlação entre a finura e a potencialização dos efeitos físicos relacionados ao FC. Neste sentido Madani e Ramezanianpour (2016) constataram a influência positiva da utilização de FC ultrafinos na resistência à compressão dos concretos, sendo que também outras propriedades como durabilidade, permeabilidade aos cloretos e resistividade elétrica também foram contempladas.

Estudos apontam para o papel de destaque da granulometria do FC (KUMAR et al., 2013; SUN et al., 2013) indicando que, à medida que a finura aumenta, melhoram as propriedades do concreto. No entanto, outros estudos, indicam um ganho na faixa de $5 \%$ a $10 \%$ de incorporação em idades precoces (TSIVILIS et al., 1999). Nesta mesma direção pode-se citar o trabalho de Lawrence et al. (2005), onde foi comparada a resistência à compressão do concreto com uma substituição por FC e filer de quartzo com equivalência de tamanho nas partículas, sendo verificado que a origem mineralógica não constituiu um parâmetro relevante. Também foi verificada a obtenção de resistências à compressão muito próximas nas diversas idades de estudo 
$(1,2,7,28,90$ e 180 dias), sendo que houve uma correlação entre aumento da finura e aumento da resistência à compressão.

O trabalho de Tsivilis (2010) sugere a existência de uma relação entre o FC na fase de ligação de uma mistura e a melhora na eficiência de empacotamento das partículas tendo em vista a finura ("efeito filer"). Este fenômeno leva a uma redução na demanda de água, reduzindo assim a exsudação do concreto, ajudando no bloqueio dos poros capilares e contribuindo para a redução da penetrabilidade.

\section{O FILER CALCÁRIO E AS PROPRIEDADES DO CONCRETO NO ESTADO FRESCO}

\subsection{O FILER CALCÁRIO E A TRABALHABILIDADE}

Um fator primordial na concepção de concretos com teores mais elevados de FC diz respeito à quantidade de água necessária para conferir uma consistência normal, desta maneira torna-se importante a diminuição do fator a/ag (PROSKE et al., 2013). A fim de se obter uma boa trabalhabilidade, com um reduzido fator a/ag, é necessário o uso de superplastificante de alto desempenho que, aliado a um empacotamento de partículas otimizado, tende a contribuir para a diminuição da demanda de água, acarretando uma diminuição no teor de clínquer (PROSKE et al., 2014).

Neste sentido a adoção de fatores a/ag, entorno de 0,35 constituem a chave para elaboração de concretos com substituição de FC de até $50 \%$ conforme Palm et al. (2016). Os autores concluem que baixos fatores a/ag (próximas a 0,35 ) constituem no mecanismo primordial para a viabilização de concretos com altos teores de substituição de CP por FC. Todavia os autores alertam que muitas propriedades do concreto fresco e endurecido dependem fortemente das propriedades físicas, ou seja, da classificação do FC, da área superficial específica BET e da composição química do FC.

É fundamental que uma trabalhabilidade suficiente seja propiciada ao concreto, dependente do tipo e quantidade das AM utilizadas. Neste sentido a adição de até 
$15 \%$ de FC pode aumentar a viscosidade, todavia diminui o atrito do fluxo de escoamento. Desta forma há que se ter em mente que a redução do fator a/ag será sempre condicionada pelas propriedades reológicas do concreto, ou seja, por ocasião da diminuição da água, a viscosidade do concreto aumentará. Contudo um projeto de empacotamento otimizado pode reduzir a viscosidade plástica do concreto em um nível adequado, mesmo com baixo teor de água a alto teor de FC (PROSKE et al., 2013). Neste tema o trabalho de El Barrak et al. (2009) demonstra que, a depender do fator a/ag, o FC possui menos influência na trabalhabilidade e age mais como agente lubrificante.

Um aspecto fundamental referente à trabalhabilidade de concretos com incorporação de FC é o da diminuição do fator a/ag e a majoração do efeito físico como relatado no trabalho de Bonavetti et al. (2003). Neste estudo os autores trabalharam em uma análise do grau de hidratação em pastas correlacionando-as com a resistência à compressão por ocasião da utilização de reduzidos fatores a/ag $(0,3$ a 0,34$)$. A conclusão foi que, para a obtenção de uma mesma qualidade de pasta, deve haver um aumento no percentual de FC incorporado com uma diminuição do fator a/ag, sendo que existe um teor ideal de FC (\%) que está atrelado à proporção da mistura do concreto.

\subsection{O FILER CALCÁRIO E O TEMPO DE PEGA}

Quanto ao tempo de pega, com base nos estudos de Hooton et al. (2007), a literatura aponta que a incorporação de FC pode trazer uma pequena modificação no tempo de pega para taxas normais de substituição (até 15\%). Neste caso, dois são os fatores preponderantes na alteração do tempo de pega: a finura e a taxa de substituição. À medida que a finura aumenta a reatividade das reações de hidratação é majorada acarretando uma diminuição no tempo de pega.

Quanto à taxa de substituição do FC, Sahmaran et al. (2006) relatam um pequeno aumento no tempo de pega para substituições correntes (até 15\%), para taxas de substituição entre 15\% e 30\% há uma diminuição no tempo de pega. El-Didamony et al. (1995) descobriram que o aumento da substituição do FC diminuiu o tempo de 
pega em pastas de CP como pode ser observado na Figura 8. É possível constatar que o tempo de início e fim de pega aumenta com a incorporação de, até, $5 \%$ no teor de FC. A partir daí ocorre uma diminuição no tempo de início e fim de pega até o teor máximo estudado de FC (20\%).

Figura 8 - Tempo de pega de pastas com FC

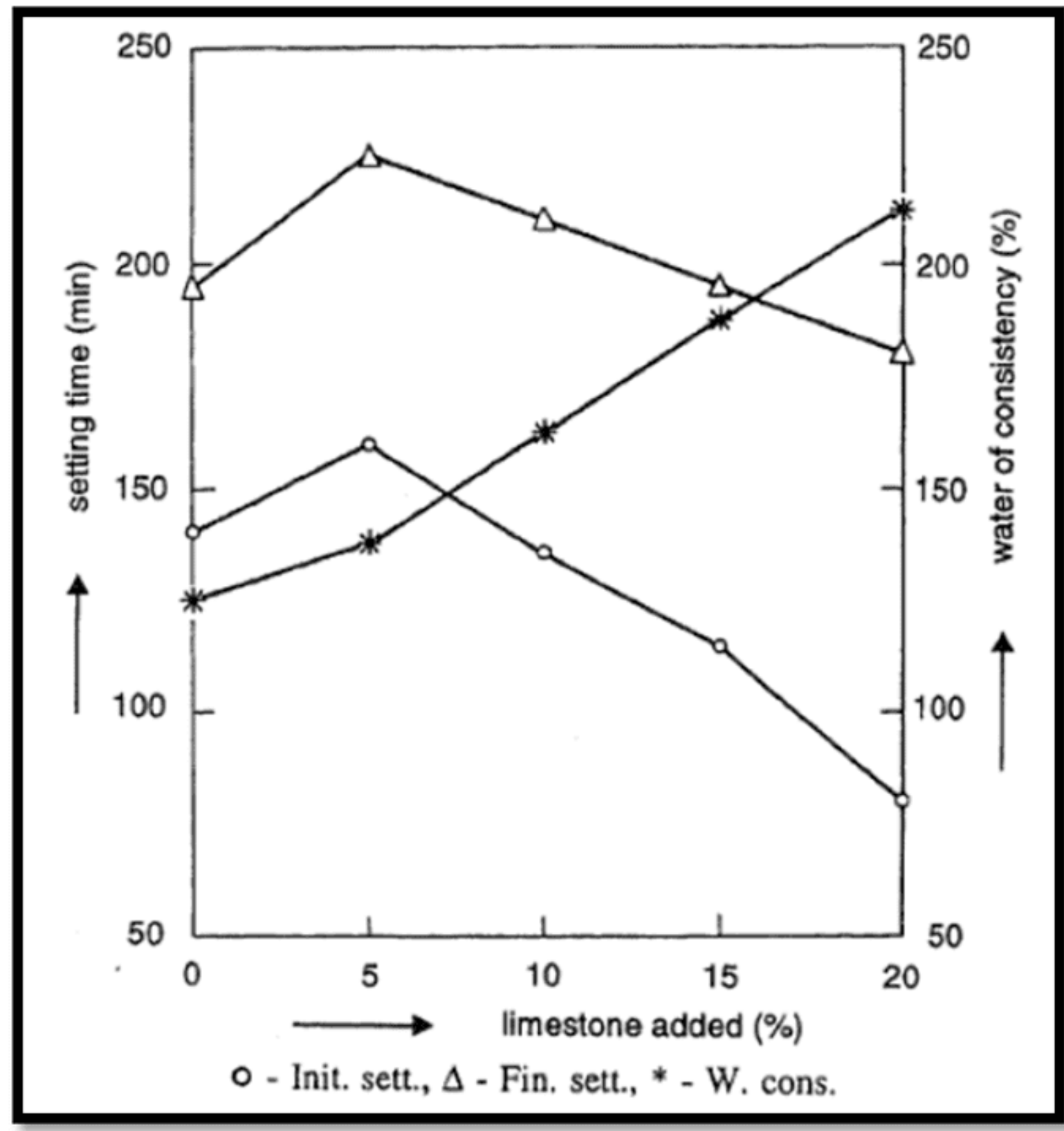

Fonte - El-Didamony et al. (1995) 
El-Didamony et al. (1995) constataram que um incremento na incorporação de FC oportunizou uma diminuição no tempo de pega das pastas de CP. De forma mais concisa Tsivilis et al. (1999) chegaram à conclusão que o FC afetou o conjunto inicial e final do tempo de pega em menor grau, geralmente diminuindo à medida que a finura aumentava. Em outra direção Moir e Kelham (1999) constataram um aumento nos tempos iniciais de pega (com $20 \%$ de substituição de $\mathrm{FC}$ ) com o aumento da finura. Nos estudos de Guemmadi et al. (2005) não foi possível realizar a correlação entre finura do $\mathrm{FC}$ e tempo de pega tendo em vista que não foi possível realizar uma correlação adequada entre as variáveis.

Pode-se encontrar na literatura uma opinião dominante de que a finura do FC influencia o tempo de pega das pastas de CP. Contudo a extensão desta contribuição difere em vários estudos. Vuk et al. (2001) estudaram diversas pastas de CP com diferentes tipos e conteúdos de $\mathrm{C}_{3} \mathrm{~S}$ entre $0 \%$ e $5 \%$ de substituição de FC. Constatouse uma diminuição nos tempos de pega inicial e final a partir do aumento da finura do FC. Sendo que a diminuição ocorreu de maneira mais pronunciada em CPs com baixa concentração de $\mathrm{C}_{3} \mathrm{~S}$.

\subsection{O FILER CALCÁRIO E O CALOR DE HIDRATAÇÃO}

Quanto ao calor de hidratação liberado, novamente, ocorre à influência da finura e a da taxa de substituição nesta propriedade. Por um lado, o aumento da taxa de substituição do CP propicia uma diminuição em compostos importantes para a geração do calor de hidratação como $\mathrm{C}_{3} \mathrm{~A}$ e $\circ \mathrm{C}_{2} \mathrm{~S}$. Por outro, o aumento da finura atua como local para a nucleação de hidratos de CP, aumentando, assim, o calor de hidratação em idades precoces (STARK, 2004). Esta constatação foi demonstrada no trabalho de Lothenbach et al. (2008) onde um cimento PC (sem adição de FC) foi comparado com um cimento PC4 (com 4\% de mistura de FC). As amostras foram ensaiadas por calorimetria de condução isotérmica, sendo que o pico de evolução térmica foi verificado após 10h para o PC4 e 11h para o PC. Tal diferença nos picos de evolução térmica indica uma ligeira aceleração na hidratação do CP a partir do FC moído. 
Figura 9 - Efeito do FC na hidratação do CP

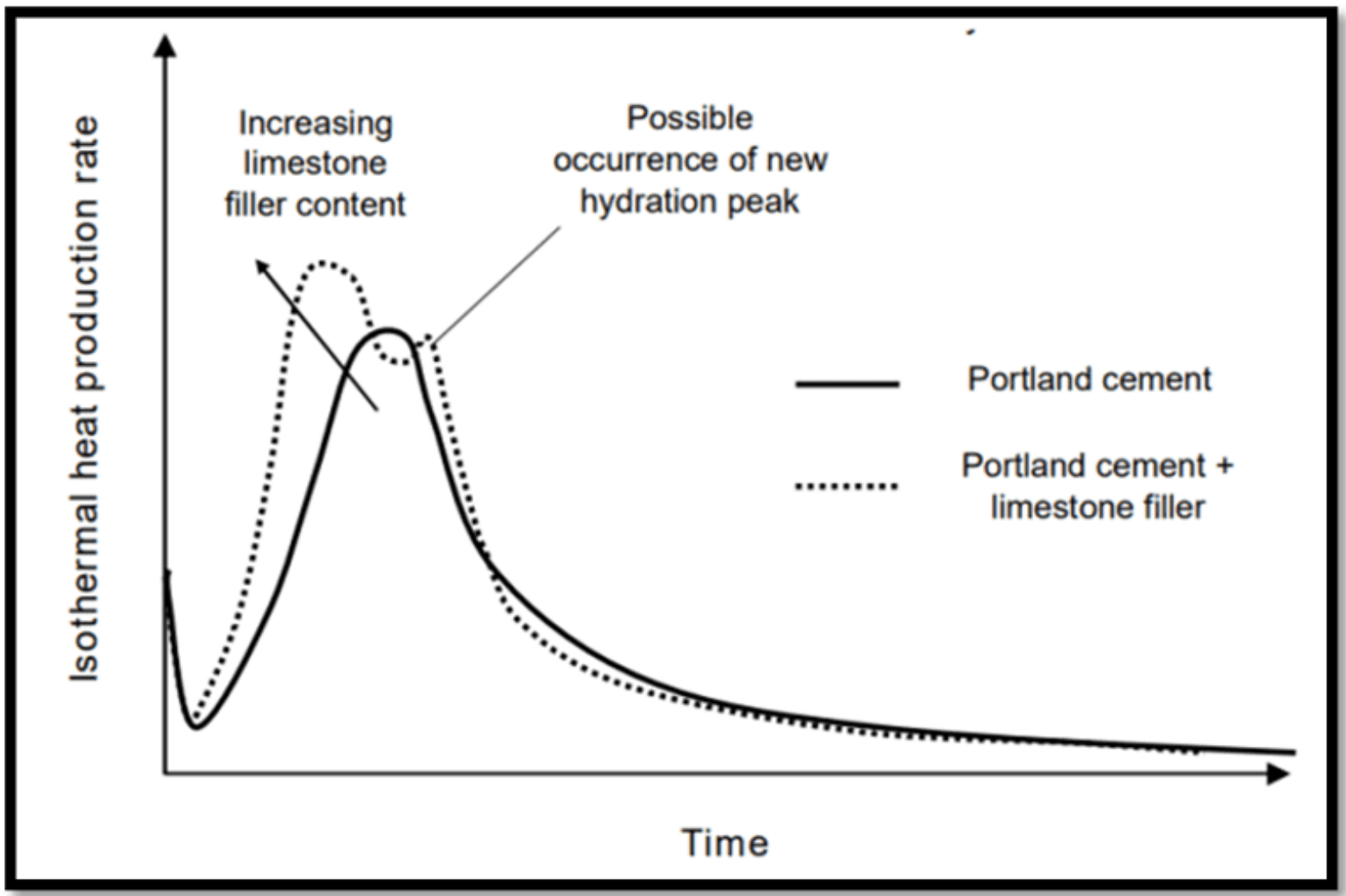

Fonte - Schutter (2011)

O mesmo efeito apresentado por Lothenbach et al. (2008), também foi verificado por Schutter (2011), onde foi possível observar o efeito do FC sobre a hidratação do CP. Na Figura 9 é possível observar a taxa de produção de calor durante a hidratação em condições isotérmicas. Com a incorporação de FC constata-se um aumento da nucleação e uma diminuição no período de indução, sendo a hidratação acelerada. É possível observar o maior valor na taxa de produção de calor isotérmico no segundo pico, o qual aumenta por ocasião da diminuição da relação CP/FC, ou seja, quando há a presença de mais FC e menos CP. Também pode ser observado um terceiro pico de hidratação que pode ocorrer em algumas combinações de $\mathrm{CP}$ (rico em $\mathrm{C}_{3} \mathrm{~A}$ ) e FC. 


\section{O FILER CALCÁRIO E AS PROPRIEDADES DO CONCRETO NO ESTADO ENDURECIDO}

\subsection{O FILER CALCÁRIO E A POROSIDADE}

Existem muitos aspectos que compõe a porosidade dos materiais à base de CP. Entre estes aspectos pode-se destacar: distribuição do tamanho dos poros, tortuosidade, superfície específica, micro rachaduras entre outros. Esses aspectos são basicamente controlados pelo fator a/ag, distribuição do tamanho da partícula, idade da amostra e tipo de materiais constituintes.

Um concreto com tamanho de poro maior, via de regra, possui uma porosidade maior do que o concreto com tamanho de poro menor. Esse efeito normalmente é refletido pelo tamanho crítico dos poros. Outro aspecto é a conectividade dos poros que consiste em um dos fatores mais críticos que influenciam a porosidade.

Estudos realizados por Ramezanianpour e Hooton (2014) mostram prospecções sobre a relação da resistência à compressão com diferentes teores de FC cujos resultados mostram que à medida que se elevou o teor de $\mathrm{FC}$ de 0 a 2,4\% houve um incremento da resistência à compressão com diminuição da porosidade.

Uma forma de explicação para este comportamento é a reação do FC com as fases de alumina do CP produzindo carboaluminatos que fornecem um aumento para a resistência mecânica por meio da produção de mais hidratos, os quais tendem a preencher os poros. Após o consumo da alumina disponível o FC adicional (acima de $2,4 \%)$ tende a não formar mais hidratos, não contribuindo para um aumento na resistência à compressão e diminuição da porosidade. No entanto deve-se levar em conta que por meio de um projeto de empacotamento adequado, bem como de uma diminuição no fator a/ag o efeito químico descrito pode ser potencializado por meio do aumento do efeito físico ("efeito filer") (RAMEZANIANPOUR; HOOTON, 2014).

Conforme Duan et al. (2013) AM como o FC podem propiciar uma diminuição na porosidade de concretos por meio do refinamento dos poros, em especial em fases 
posteriores a cura. O FC por meio do efeito físico leva a uma diminuição substancial no volume de poros trazendo deslocamento na distribuição do tamanho dos poros na direção dos pequenos diâmetros. Ocorre, então, a colmatação dos espaços entre as partículas de CP por meio do $\mathrm{FC}$ o que confere à pasta uma maior densidade com aumento da resistência à compressão.

Barbhuiya et al. (2015) trabalharam com partículas muito finas de AM por meio da adição de metacaulim em pastas de $\mathrm{CP}$, foi constatado uma menor porosidade quando comparado com pastas sem metacaulim. $O$ estudo destaca o efeito físico de empacotamento do metacaulim devido sua finura em relação ao $\mathrm{CP}$ da mesma forma que o FC. Outro aspecto levantado pelos autores diz respeito ao efeito bloqueador dos poros advindo do metacaulim que potencializa a redução da interconexão dos mesmos.

Ensaios de Lothenbach et al. (2008) atestam a contribuição do efeito físico/químico do FC na resistência à compressão do concreto por meio da diminuição da porosidade. Os autores afirmam que a incorporação do FC contribui para a formação de monocarboaluminatos que estabiliza a etringita proporcionando um aumento de volume das fases hidratadas levando a redução da porosidade como um todo.

\subsection{O FILER CALCÁRIO E A RESISTÊNCIA À COMPRESSÃO}

No que diz respeito à contribuição do FC para a resistência à compressão do concreto, vários são os estudos que abordam o assunto, Soroka e Setter (1977) apontam para um incremento na resistência à compressão mesmo com o aumento da substituição de FC. Os autores indicam que o ganho de resistência ocorreu, preponderantemente, por efeito físico, ou seja, por um aumento na densidade da mistura. Da mesma forma Palm et al. (2016) em sua pesquisa concluíram que o FC não é um componente totalmente inerte e que a sua contribuição para a resistência à compressão também é notável sendo proporcional a quantidade de CP substituída.

Um ponto que merece destaque foi apresentado no trabalho de Bonavetti et al. (2003) que relaciona o fator a/ag com a amplitude do efeito físico, ou seja, o aumento da 
resistência à compressão na medida em que o fator a/ag diminui. $\mathrm{O}$ trabalho de Feltrin et al. (2016), Figura 10, representa a relação proposta pelo autor anterior, ou seja, à medida que o fator a/ag diminui para 0,35 a resistência à compressão é majorada juntamente com o aumento do teor de FC enquanto que, para um fator a/ag 0,50, há equivalência e, para 0,65 , diminuição da resistência à compressão com o aumento do teor de FC. Neste caso o fator a/ag possui um papel decisivo no aumento das resistências à compressão à medida que o teor de FC é majorado conforme o estudo de Palm et al. (2016).

Figura 10 - Efeito do FC na resistência à compressão

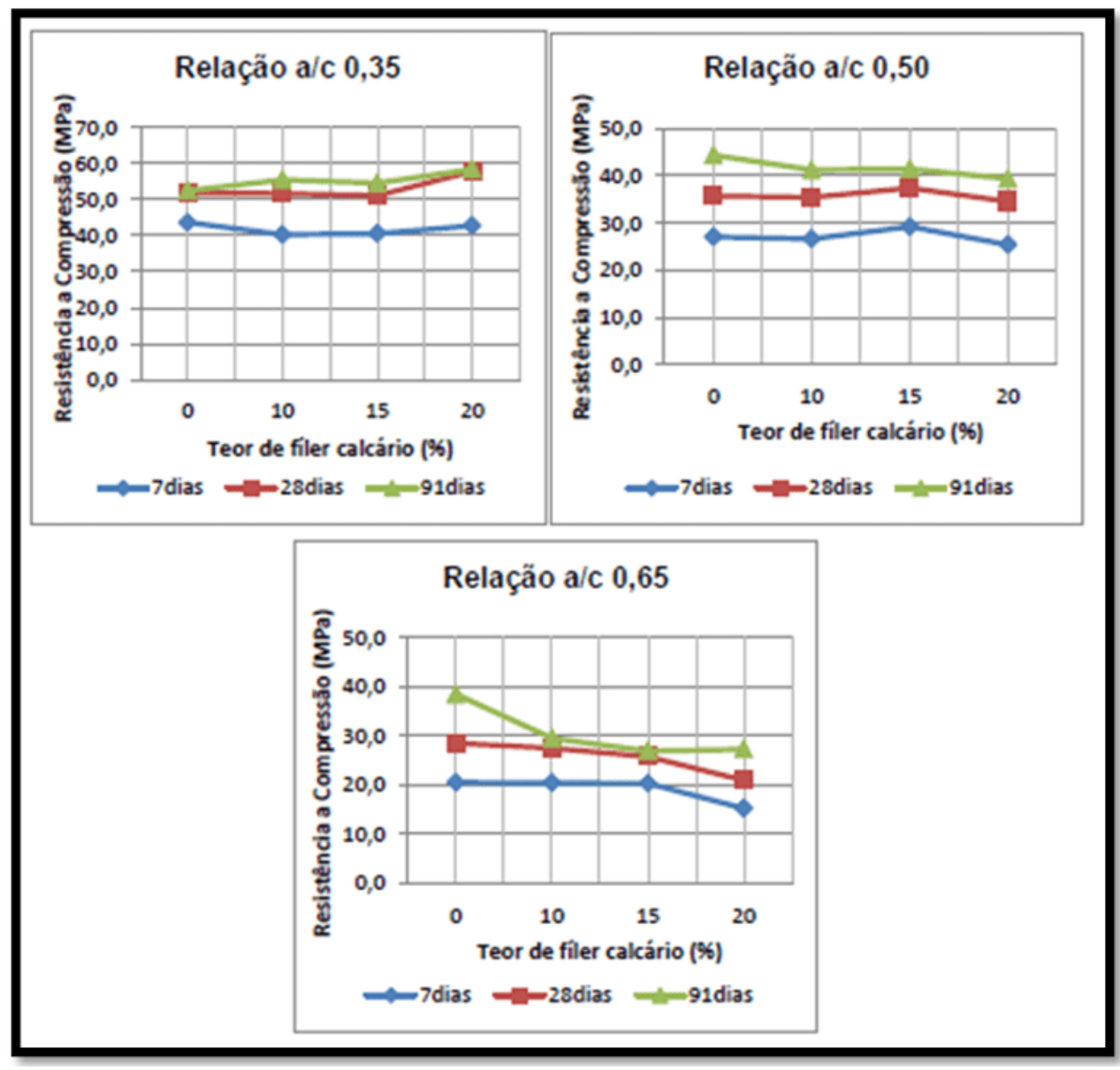

Fonte - Feltrin et al. (2016)

O trabalho de Damineli (2013) confirma esse comportamento ao estudar 15 tipos diferentes de fileres com dois tipos de CPs sem adições, em argamassas para um 
mesmo fator a/ag de 0,5 . A substituição dos fileres foi de $50 \%$ em relação à massa de $\mathrm{CP}$. Tendo em vista a importância da granulometria do filer quanto ao efeito físico, foi levado em conta o princípio do empacotamento de partículas, sendo estudados diferentes agregados com diversas faixas granulométricas. $O$ estudo chegou à conclusão que todas as misturas com filer resultaram em resistências superiores às argamassas de referência somente com CP.

Em sentido oposto Dhir et al. (2007) mostraram que a resistência à compressão diminuiu com o teor de FC com níveis de adição na faixa de $15 \%$ a $45 \%$. Nota-se que no estudo a resistência à compressão é reduzida em todas as idades com o aumento do teor de FC, conforme pode ser visto na Figura 11 A redução de resistência com $15 \%$ de FC é relativamente pequena, no entanto, em níveis mais altos, a redução na resistência à compressão está relacionada à redução no teor de CP. Desta forma, concretos com substituição acima de $15 \%$ de FC deveriam ter um redução do fator a/ag de 0,08 para cada $10 \%$ de incorporação a fim de se obter resistências à compressão equivalentes aos 28 dias. 
Figura 11 - Efeito da substituição de CP por FC em relação à resistência à compressão do concreto
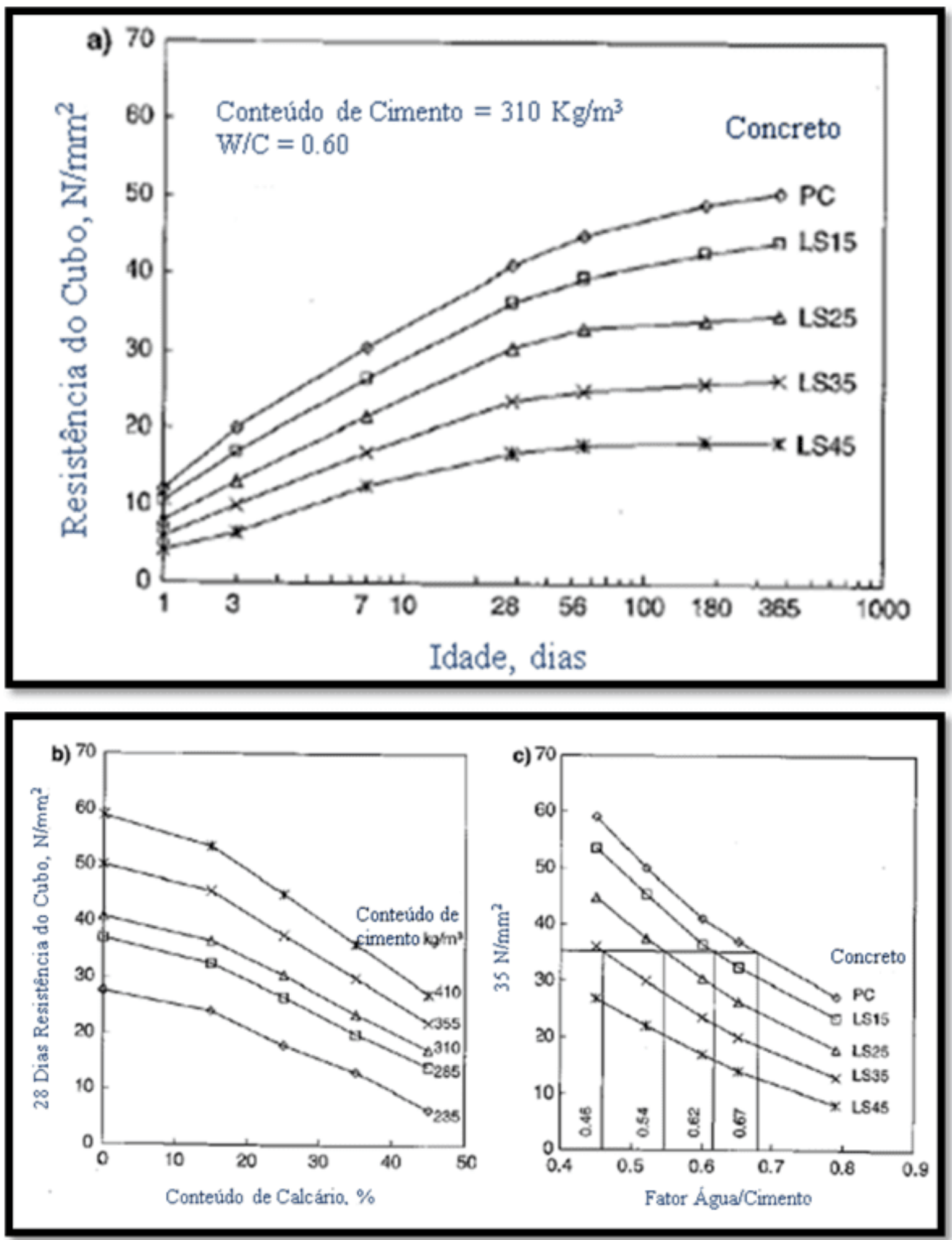

Fonte - Dhir et al. (2007)

RC: 71092

Disponível em: https://www.nucleodoconhecimento.com.br/engenharia-civil/calcario-no-concreto 
Outro trabalho similar é de Madani e Ramezanianpour (2016) onde foi concluído que a utilização de FC ultrafinos não trouxe um incremento na resistência à compressão. Todavia o reflexo da incorporação de FC na durabilidade mostrou-se positiva, em especial na permeabilidade aos cloretos e a resistividade elétrica.

A diferença nas conclusões dos trabalhos citados deve-se ao tipo de FC, sua granulometria, bem como da maneira que o empacotamento de partículas foi realizado e do fator a/ag empregado em cada mistura. Contudo, parecem bastante plausíveis as conclusões de Dhir et al. (2007), onde se justifica a diminuição da resistência à compressão nos concretos devido ao aumento nos teores de FC, por meio da redução no teor de CP através do efeito diluição.

\section{O FILER CALCÁRIO E A DURABILIDADE}

\subsection{O FILER CALCÁRIO E A CARBONATAÇÃO}

À medida que aumenta o teor de substituição de CP por AM, há alteração no teor de C-S-H formado. Se adição for ativa, há formação adicional de C-S-H secundário, se inerte, como o FC, o teor de C-S-H diminui e aumenta ligeiramente o de C-A-S-H, este balanço depende dos compostos formados, do empacotamento de partículas, da estrutura dos poros e do fator a/ag. A quantidade de $\mathrm{C}-\mathrm{S}-\mathrm{H}$ resultante das reações de hidratação implica, em um efeito diretamente proporcional na formação de Portlandita, pois ambos compostos são participantes da mesma reação química, em proporções recíprocas. Assim, quanto maior a substituição de $\mathrm{CP}$ por FC haverá menor formação tanto de C-S-H quanto de Portlandita, que se reflete nas propriedades relacionadas com a durabilidade, de acordo com os mecanismos físico-químicos envolvidos.

Assim, quanto aos processos envolvidos na carbonatação de concretos, dois parâmetros básicos precisam ser levados em conta: a) a reserva alcalina, medida pelo teor de Portlandita remanescente; b) a estrutura dos poros, avaliada indiretamente pela resistência à compressão. Grande parte dos pesquisadores que estudam a incorporação de FC em concretos e argamassas concorda que a substituição do CP 
diminui a reserva alcalina podendo acarretar uma maior carbonatação, dependendo do tipo, teor e granulometria desta adição.

Entretanto, a diminuição da reserva alcalina pode ser compensada por modificações na estrutura de poros com vistas à obtenção de uma microestrutura mais homogênea, pelo estudo da dosagem dos materiais finos através de um empacotamento de partículas mais fechado, resultando em menor teor de vazios e resistência à compressão mais alta. Essa estratégia conduzirá à obstrução da percolação do $\mathrm{CO}_{2}$ e de outros fluidos pela microestrutura mais compacta, dependendo do empacotamento das partículas, do teor do FC, do tipo e quantidade de aditivos utilizados e, principalmente, do fator a/ag.

Quando se trata de carbonatação em concretos com substituição do CP por FC existem várias posições sobre o assunto, alguns autores afirmam que a substituição leva a um aumento da taxa de carbonatação em relação ao concreto com o mesmo fator a/ag. De outro lado autores como Tsivilis et al. (2003) defendem que a resistência a carbonatação não é minorada mesmo com a substituição de $35 \%$ de FC. Lollini et al. (2014) constataram uma diminuição relevante na resistência à carbonatação para um nível de substituição de $30 \%$ de FC e nenhum efeito claro com $15 \%$.

No estudo de Elgalhud et al. (2018) foi observado à influência do teor de FC na carbonatação do concreto para um mesmo fator a/ag. Observou-se um aumento da carbonatação tanto natural quanto acelerada com o aumento de substituição de $\mathrm{CP}$ por FC, tendo em vista que o CP utilizado foi o CEM IV que já apresenta substituição de clínquer por pozolana, o que resulta em carbonatação adicional com o aumento do conteúdo de FC.

Vários estudos demonstram que a taxa de carbonatação é semelhante em concretos com a mesma resistência à compressão, independentemente da quantidade de FC que substitui o CP. Para que isto aconteça é necessária à diminuição do fator a/ag e aumento da quantidade de FC (BARKER; MATTHEWS, 1994; LIVESEY, 1991). 
Tal comportamento pode ser observado na Figura 12 onde é possível verificar a profundidade de carbonatação aos 5 anos de idade em relação à resistência à compressão aos 28 dias de idade no concreto. É possível observar que, concretos com a mesma resistência à compressão, a profundidade de carbonatação será praticamente a mesma independentemente da quantidade de FC substituído.

Figura 12 - Profundidade da carbonatação como função da resistência para o concreto produzido com CP com níveis variáveis de FC

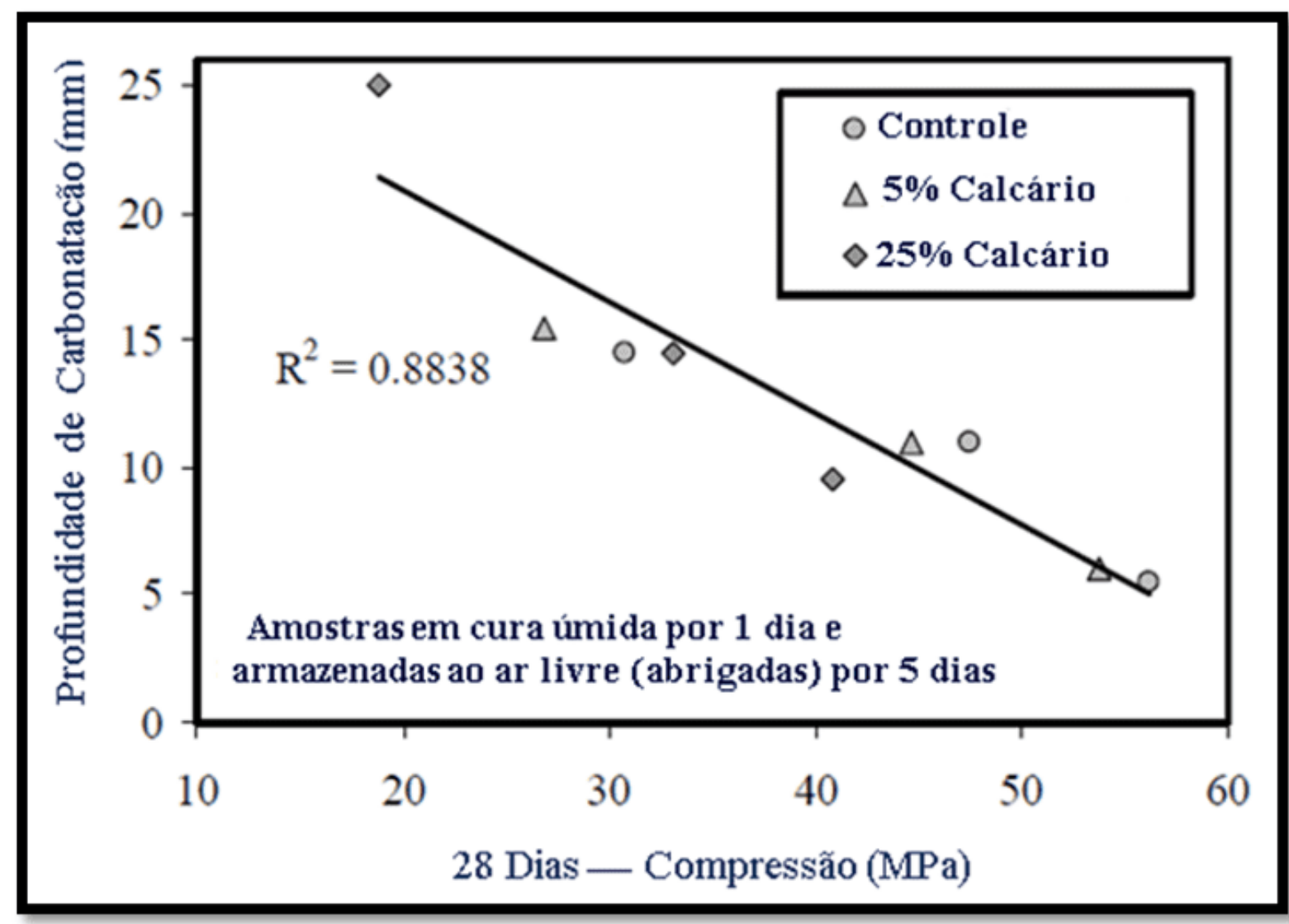

Fonte - Barker e Matthews (1994)

Desta maneira pode-se dizer que a carbonatação não é, necessariamente, uma função da substituição de CP por FC porque, ao ajustar-se o fator a/ag mantendo-se a resistência constante é possível à obtenção de concretos com desempenho mecânico (resistência à compressão) e de durabilidade (profundidade de carbonatação) adequados. Este raciocínio é válido para concretos normais com taxa de substituição de CP por FC até $15 \%$. 
A tendência apresentada não fica restrita a baixos teores de FC (5\% a $10 \%)$, substituições até $35 \%$ de FC mostram comportamento semelhante (TSIVILIS et al., 2002). Concreto produzido com $45 \%$ de FC mostrou resistência similar à carbonatação quando comparado ao sem substituição do mesmo grau de resistência (HOOTON et al., 2007). Nas misturas com altos teores de FC, empregando-se fatores a/ag menores com aditivos superplastificantes e adequado estudo de empacotamento das partículas, a resistência à compressão pode ser majorada, levando a uma redução da taxa de carbonatação.

\subsection{O FILER CALCÁRIO E A RESISTÊNCIA AO CLORETO}

Em relação à substituição de $\mathrm{CP}$ por $\mathrm{FC}$ e a resistência à penetração de íons cloretos Hornain et al. (1995) relataram uma diminuição do coeficiente de difusão devido ao "efeito filer", tendo em vista o aumento da compacidade da matriz cimentícia. Por outro lado Bentz et al. (2009) e Ghrici et al. (2007) defendem que há um aumento da penetração de íons cloreto com a substituição de FC em comparação com concretos sem substituição. $O$ aumento na penetração de íons cloreto deve-se a reação do FC com os aluminatos do $\mathrm{CP}\left(\mathrm{C}_{3} \mathrm{~A}\right.$ e $\left.\mathrm{C}_{4} \mathrm{AF}\right)$, bem como a formação de compostos que possuem uma menor capacidade de ligação em relação aos cloretos (FAGERLUND, 2005). 
Figura 13 - Efeito do FC na penetração de cloreto no concreto

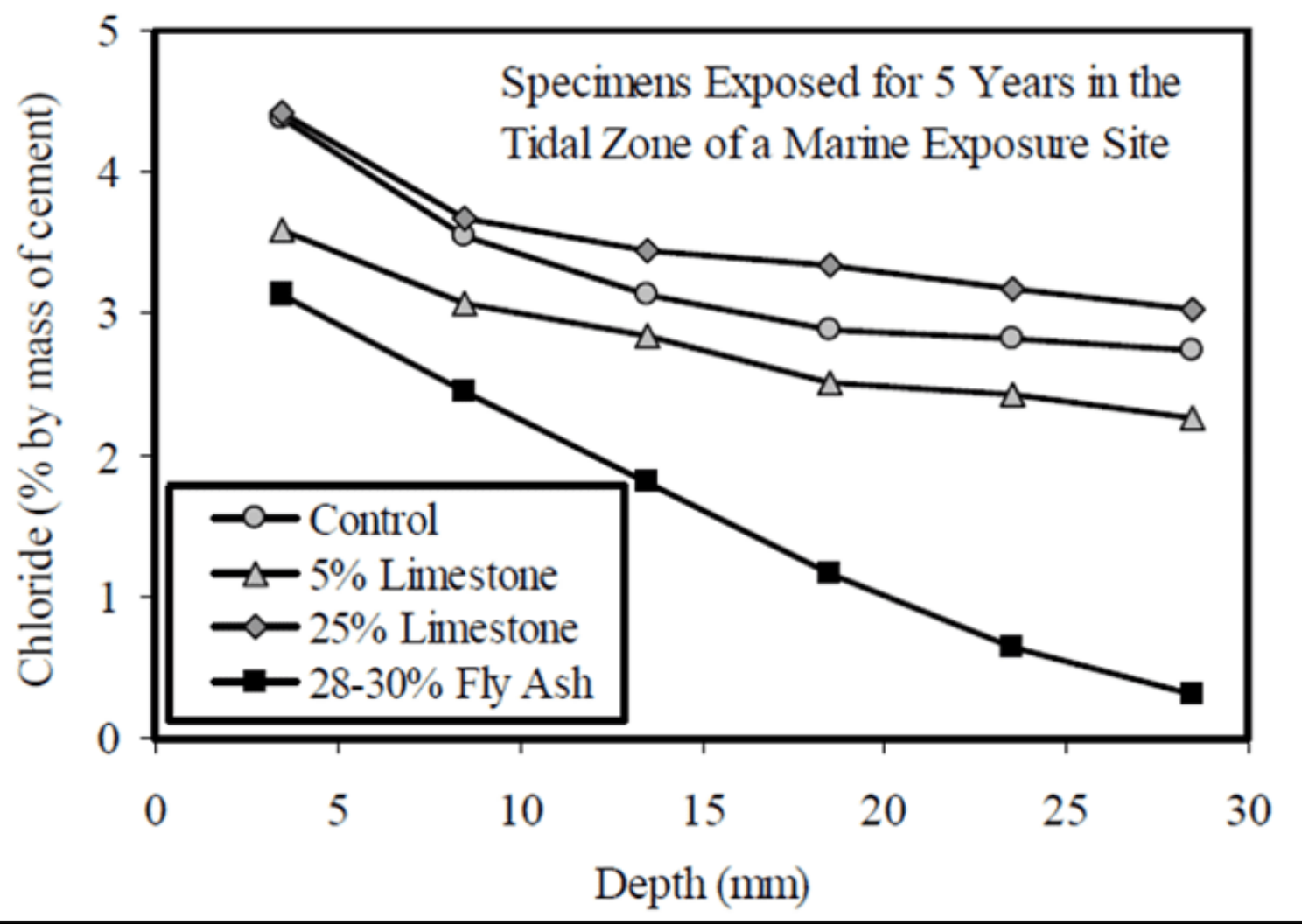

Fonte - Matthews (1994)

Em outra linha alguns autores defendem uma substituição limitada do CP por FC (até 15\%) alegando que esta proporção de substituição não afeta de maneira acentuada a resistência à penetração de cloretos (DIHR et al., 2007; TSIVILIS et al., 2002). Matthews (1994) conduziu um estudo onde prismas de concreto foram submetidos à zona de maré. Na Figura 13 é possível observar os perfis de concentração de cloreto após 5 anos de exposição. Para todas as misturas produzidas foram calculadas as médias dos resultados tendo em vista o mesmo conteúdo de FC. Uma resistência um pouco maior foi constatada com concretos produzidos com 5\% de FC, enquanto uma resistência um pouco menor foi constatada para uma substituição de $25 \%$. Contudo os melhores resultados foram obtidos com a incorporação de CV na mistura.

Em um estudo em concretos com 5 CPs diferentes e com conteúdo de FC variando entre $0 \%$ e $35 \%$ de FC, Tsivilis et al. (2000) conduziram o "Teste de Permeabilidade 
Rápida de Cloreto, RCPT" após 28 dias de cura úmida. Neste caso não foi possível observar mudanças relevantes nas misturas entre $15 \%$ e $20 \%$. A mistura onde foi constatado o maior valor de RCPT foi de $35 \%$ de substituição de FC, mesmo sendo a que foi moldada com menor fator a/ag, indicando que neste nível de substituição a permeabilidade a cloretos pode aumentar.

Irassar et al. (2001) elaboraram concretos contendo FC com substituição de 0\%, 10\% e $20 \%$, os quais foram imersos em solução de $\mathrm{NaCl}$ a $3 \%$. Foram determinados os perfis de cloreto após vários períodos de exposição, sendo os coeficientes de difusão de cloretos determinados a partir dos perfis. Tanto para o aumento do fator a/ag e substituição de FC (\%), pode-se observar aumentos importantes no coeficiente de difusão de cloretos. O desempenho do concreto produzido com o maior fator a/ag e \% de substituição de FC obteve um desempenho muito baixo em relação à penetração dos íons cloretos.

\subsection{O FILER CALCÁRIO E A PERMEABILIDADE}

Um estudo sobre permeabilidade ao oxigênio em concretos foi desenvolvido por Matthews (1994), onde uma gama de diferentes CPs foi utilizada com um fator a/ag de 0,6 . Cinco diferentes $\mathrm{CP}$ foram utilizados na pesquisa, sendo um deles intercalado com $5 \%$ e $25 \%$ de FC, e o restante misturado com $5 \%$ ou $25 \%$ de FC. Um dos CPs foi misturado com $30 \%$ de CV e outro foi intercalado com $28 \%$ de CV. Na Figura 14 é possível observar os resultados da permeabilidade. De maneira geral pode ser constatado uma diminuição da permeabilidade com o aumento da substituição de CP por FC. Os autores concluíram que as diferenças nos resultados obtidos são pequenas por ocasião da comparação com as reduções advindas da cura prolongada. 
Figura 14 - Efeito da incorporação de FC sobre a permeabilidade do concreto

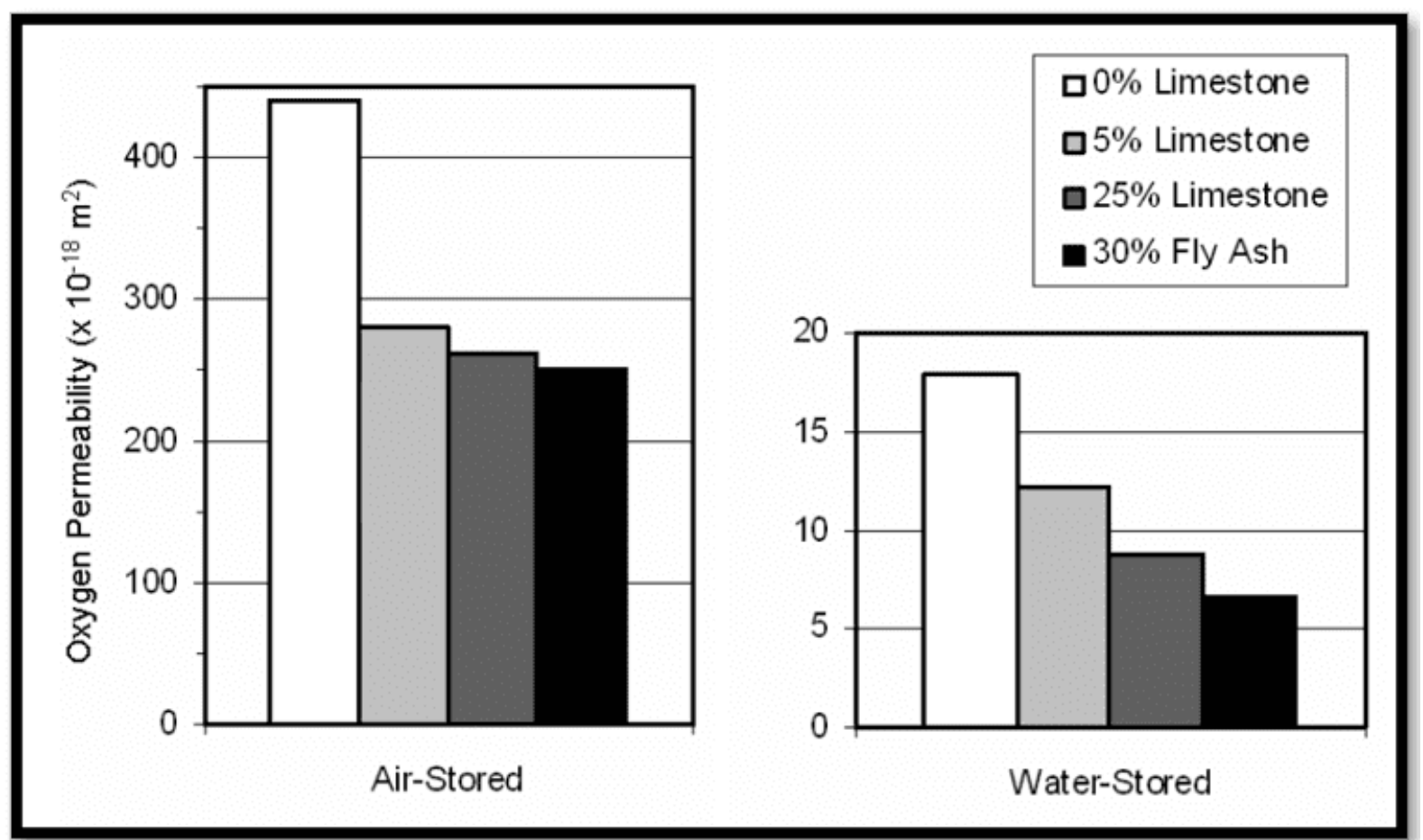

Fonte - Matthews (1994)

Concretos com 7 diferentes tipos de CP foram produzidos por Tsivilis et al. (2003), onde foi foram realizados ensaios para a medição da permeabilidade ao gás, à água, bem como absorção e porosidade. A elaboração do concreto ocorreu por meio de CPs que foram produzidos em uma planta piloto em um moinho de bolas por intermoagem. As duas principais variáveis foram o teor de substituição do $\mathrm{FC}$ e a finura do $\mathrm{CP}$ intermoído. Para tanto os concretos foram curados até a idade de 28 dias antes da realização dos ensaios.

Em relação aos resultados obtidos foi observado que os maiores coeficientes de permeabilidade ao gás ocorreram nos concretos elaborados com FC quando comparados aos sem incorporação de FC. A exceção foi verificada no concreto com $35 \%$ de FC que apresentou a menor permeabilidade ao gás. Um ponto a ser destacado diz respeito aos concretos com FC que apresentaram permeabilidade reduzida à água e menores valores de absorção de água. 
Constatou-se, também, que não ocorreu diminuição da porosidade nos concretos com, até, $15 \%$ de FC incorporado. Por outro lado foi constatado um aumento da porosidade nos concretos que possuíam a maior substituição de CP por FC. Tendo em vista os resultados obtidos, os autores puderam concluir que os concretos produzidos com a incorporação de FC possuíam, de modo geral, "propriedades competitivas" quando comparados aos concretos elaborados sem FC.

\section{O FILER CALCÁRIO E OS ALTOS TEORES DE SUBSTITUIÇÃO}

Estudos realizados nas últimas três décadas para investigar o desempenho do FC no CP mostram que os teores de substituição estão aumentando, entretanto, ainda existem controvérsias com respeito ao comportamento reológico, mecânico e à durabilidade, com resultados discrepantes (LOLLINI et al., 2014). Alguns estudos demonstram que concretos com baixo fator a/ag $(<0,4)$ boa parte do CP continua sem hidratação, pois não há espaço para alojar os compostos, especialmente a Portlandita, desta forma o CP pode ser substituído por partículas mais econômicas como o FC (BENTZ, 2006; BONAVETTI et al., 2003).

À medida que o teor de $\mathrm{FC}$ aumenta na pasta de $\mathrm{CP}$, sem controle granulométrico da quantidade de água, o fator a/ag aumenta e o desempenho diminui. Para melhorar esse comportamento é preciso diminuir a água, aumentar a mobilidade das misturas com superplastificantes e, principalmente, controlar arranjo entre partículas para diminuir os vazios pelo aumento da compacidade entre os grãos de CP e FC, ou da pasta com os agregados. Segundo Fennis e Walraven (2012) é possível conceber concreto com baixa emissão de $\mathrm{CO}_{2}$, onde $50 \%$ do $\mathrm{CP}$ é substituído por $\mathrm{AM}$, usando tecnologia de empacotamento de partículas na otimização das misturas.

John et al. (2018) ensejam a propositura de uma nova visão a respeito da diminuição dos teores de CP ao proporem uma inovadora tecnologia. Ela se baseia em uma metodologia que propõe a utilização de baixos teores de CP e altos teores de FC, combinando o uso de dispersantes com a finalidade de reduzir o teor de água para, assim, compensar a diluição. 
Com a implementação desta tecnologia, os altos teores de FC são compensados através da diminuição do consumo de água, por meio do empacotamento de partículas e dispersão. Conforme os autores obtêm-se intensidades de $\mathrm{CO}_{2}$ resultantes que equivalem àquelas obtidas pela substituição do $\mathrm{CP}$ por outras $\mathrm{AM}$ mais reativas como a $C V$ e a $E A F$, as quais são classificadas como neutras em relação à emissão de $\mathrm{CO}_{2}$ por serem considerados resíduos.

Destacam-se, entre as formulações apresentadas, algumas que utilizam CP e altos teores de $\mathrm{FC}$, as quais possuem um impacto de $\mathrm{CO}_{2}$ que equivalem aos concretos produzidos com tecnologia atual. Entretanto as contribuições desta tecnologia não poderão trazer todos os benefícios esperados, tendo em vista que ainda vigora, na maioria dos padrões, um conteúdo mínimo de CP, a despeito da literatura colocar em cheque a necessidade do mesmo. Por outro lado em alguns países esta limitação poderá ser superada por meio de uma abordagem de desempenho equivalente (JOHN et al., 2018).

Na mesma linha de John et al. (2018), Proske et al. (2013) colocam que o desempenho do concreto feito de CP com um teor de substituição de FC entre 20 e $35 \%$ em peso e fatores a/ag comuns é crítico. Uma durabilidade desejável do concreto não pode ser alcançada, a menos que o fator a/ag seja reduzido. Os princípios para o desenvolvimento de um concreto com CP reduzido (altos teores de FC) são descritos por Proske et al. (2013) da seguinte maneira: a) uso de superplastificante de alto desempenho; b) a otimização da densidade de empacotamento. Estes dois princípios permitem a redução da demanda de água e, portanto, simultaneamente, a minimização do teor de CP.

Neste sentido a redução do fator a/ag (necessária para concretos com alto teor FC) é limitada pelos requisitos das propriedades reológicas. Se o teor de água for reduzido, a viscosidade plástica do concreto geralmente aumentará. Proske et al. (2013) concluíram que a modificação na distribuição granulométrica das partículas e consequentemente do concreto pode reduzir a viscosidade plástica em uma extensão aceitável, mesmo para concretos com baixo teor de água e alto teor de FC. Ainda no que tange a quantidade de água em concretos com elevados teores de FC, Proske et 
al. (2013) observaram que todos os concretos elaborados com substituição de $50 \%$ de FC em peso tinham uma trabalhabilidade aceitável.

Palm et al. (2016) realizaram uma pesquisa sobre a utilização de altos teores de FC (> 50\%) em substituição ao CP. Neste trabalho os autores estudaram as propriedades mecânicas, de durabilidade e características ecológicas dos concretos elaborados com altos teores de FC, obtendo as seguintes conclusões: a) os resultados mostram que concretos com CP contendo até $50 \%$ de $\mathrm{FC}$ e um fator a/ag 0,35 podem ter propriedades suficientes para aplicação prática se uma supervisão rigorosa for assegurada. Além disso, esses concretos podem exibir propriedades mecânicas e de durabilidade comparáveis aos concretos tradicionais; b) o fator a/ag é o principal parâmetro para concretos com alto teor de FC. As propriedades mecânicas e de durabilidade dependem quase que exclusivamente deste parâmetro. No entanto, muitas propriedades de concreto no estado fresco e endurecido dependem fortemente das propriedades físicas, isto é, da classificação, da área superficial específica BET e da composição química do $\mathrm{FC}$; c) os resultados mostraram que o $\mathrm{FC}$ parece não ser totalmente inerte. A contribuição do FC para a resistência à compressão também é notável quando uma quantidade maior de CP é substituída por FC; d) partes do FC devem ser moídas mais finas que o CP para servir como locais de nucleação e, portanto, melhorar o progresso da hidratação. Outras partes do FC devem ser mais grosseiras do que o CP para fornecer uma distribuição mais ampla do tamanho de partícula e, portanto, uma melhor densidade de empacotamento e menor demanda de água; e) todos os concretos feitos com 50\% de FC e fator a/ag 0,35 tinham pelo menos uma resistência à compressão igual ou superior à das misturas de referência com fator a/ag 0,50. Foi visível que, para CPs de proporção água/clínquer constantes com maior teor de FC, tenha ocorrido sistematicamente uma resistência à compressão mais alta; f) para concretos com $50 \%$ de $\mathrm{FC}$, uma resistência à carbonatação semelhante ao concreto de referência foi obtida quando o fator a/ag foi reduzida para 0,$35 ; \mathrm{g}$ ) concretos com fator a/ag 0,35 apresentaram coeficientes de migração inferiores a $20.10^{-12} \mathrm{~m}^{2} \cdot \mathrm{s}^{-1}$, comparáveis com as duas misturas de referência; $h$ ) a taxa de retração de concretos com $50 \%$ de FC é altamente dependente da qualidade do FC. A comparação das deformações por retração após 112 dias revela que a mistura com 
$50 \%$ de FC apresentava um valor de retração comparável aos dos concretos de referência; i) o comportamento em relação à fluência dos concretos com $50 \%$ de FC foi semelhante a da retração.

\section{A SUSTENTABILIDADE DO FILER CALCÁRIO}

Levando-se em conta o aumento na demanda de CP que ocorrerá nas próximas décadas, a indústria cimenteira não poderá fazer uso das tradicionais estratégias de mitigação das emissões de $\mathrm{CO}_{2}$. Uma solução aventada, até pouco tempo, para a mitigação da emissão de $\mathrm{CO}_{2}$ foi à captura e armazenamento de carbono (CCS). Apesar de já ter sido apontada como solução inevitável por boa parte dos líderes da indústria do CP a CCS tem sido considerada custosa e com alto risco ambiental (IEA, 2009).

Outro componente deste problema diz respeito à limitação da oferta de CV e EAF que irão representar menos de $20 \%$ da demanda global de CP até 2050. A partir da crise do petróleo na década de 1970 iniciaram os estudos para a utilização do FC como substituto parcial do CP. Desde a década de 1990 o uso de FC foi padronizado como substituição parcial do CP (KLIEGER; HOOTON, 1990; MAYFIELD, 1988).

As taxas de redução de $\mathrm{CO}_{2}$ na produção do $\mathrm{CP}$ são proporcionais à substituição de FC, tendo em vista que ele não requer calcinação. Com a utilização de FC, há uma redução na energia térmica consumida, bem como nas emissões de $\mathrm{CO}_{2}$. Outro aspecto importante diz respeito ao aumento da vida útil das jazidas de matérias primas. Também se destaca o fato que a diminuição na emissão de $\mathrm{CO}_{2}$, tornou-se uma parte comercial do produto CP.

Com a utilização de FC, menos clínquer deve ser produzido, assim sua utilização constitui-se em uma solução que agrega aspectos técnicos e de sustentabilidade. Com isso para uma dada quantidade de $\mathrm{CP}$ há um consumo menor de energia, bem como são mitigadas parte das emissões de GEE. Duas são as principais fontes de emissões de $\mathrm{CO}_{2}$ na indústria cimenteira. Em primeiro lugar está calcinação do calcário, principal ingrediente bruto para a fabricação de clínquer. Em segundo lugar 
o consumo de combustível fóssil para aquecer as matérias-primas até a temperatura necessária para a formação do clínquer.

O calcário possui cerca de $50 \%$ em massa de $\mathrm{CO}_{2}$, sendo a liberação deste gás, no processo de calcinação, o responsável por $60 \%$ das emissões $\mathrm{CO}_{2}$ produzidas em uma fábrica de CP. Estas quantidades de emissões são mitigadas, em parte, por ocasião da utilização de FC, pois menos clínquer é usado na produção do CP. Estudos apontam que as reduções nas emissões de $\mathrm{CO}_{2}$ são proporcionais à diminuição da quantidade de clínquer no CP misturado. É fato que esta mesma contribuição (diminuição na emissão de $\mathrm{CO}_{2}$ ), também, pode ser obtida com o uso de CV e EAF. Não obstante a utilização do FC possui um "bônus ambiental', pois está prontamente disponível em todas as fábricas de CP do mundo.

Figura 14 - Emissões específicas de $\mathrm{CO}_{2}$ da produção de $\mathrm{CP}$ para 3 fábricas na Alemanha

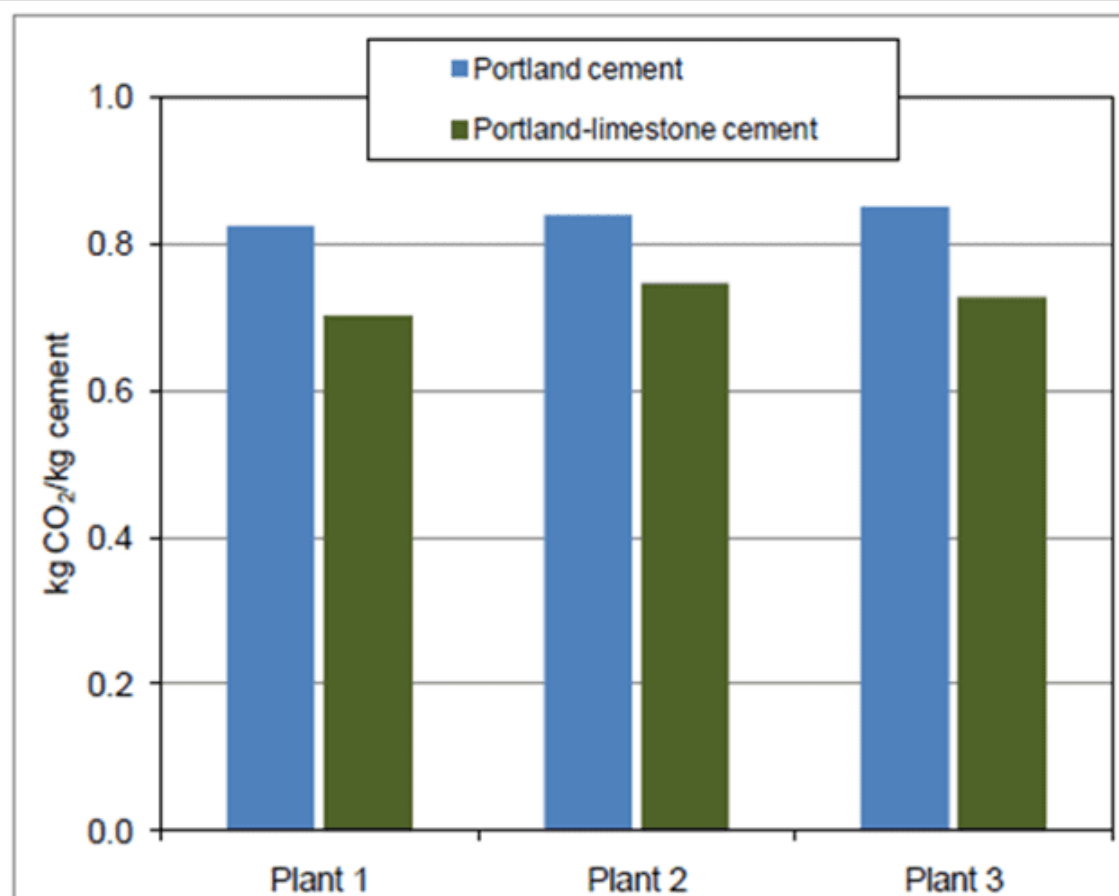

Fonte - Schmidt et al. (1992) 
Na Figura 14 é possível observar o trabalho realizado por Schmidt et al. (1992), onde são mostrados exemplos específicos referentes à redução das emissões de $\mathrm{CO}_{2}$ em três fábricas de CP na Alemanha. Nos referidos cálculos foram incluídos a totalidade da demanda de energia referente a todas as etapas do processo produtivo. Para tanto foi considerada a demanda específica de energia para o combustível. Os autores chegaram à conclusão que a substituição de 15\% em massa do clínquer por FC reduziu as emissões de $\mathrm{CO}_{2}$ em $12 \%$. Resultados similares podem ser obtidos para as emissões de $\mathrm{NO}_{x}$ e $\mathrm{SO}_{2}$.

Um aspecto que deve ser analisado diz respeito ao uso de energia e emissões de $\mathrm{CO}_{2}$ relacionadas ao transporte da CV ou EAF. Este passivo energético e ambiental não está presente por ocasião da utilização do FC. Via de regra os CP com FC são mais finos que os CP comuns (sem substituição), sendo necessário, portanto, um consumo maior de energia durante a etapa de moagem. Entretanto este gasto energético maior é amplamente compensado com a diminuição na produção de clínquer. Assim o saldo líquido em relação as emissão de $\mathrm{CO}_{2}$ é menor.

Outro impacto ambiental positivo na substituição do clínquer por FC reside no fato de uma menor demanda de matéria-prima, reduzindo consequentemente o consumo de recursos naturais. Utilizando-se dados médios, pode-se dizer que são necessárias de 1,3 a 1,4 toneladas de matérias-primas para a produção de 1 tonelada de CP. Com a utilização do FC há uma redução de 10\% no consumo de matérias-primas.

Desde o início da década de 1990 a utilização de CP contendo FC na Europa teve um aumento de 4 vezes. Vários são os fatores que explicam o incremento na demanda, entre eles destacam-se os suprimentos limitados de materiais cimentícios tradicionais, como CV e EAF e o custo relativo do FC (DAMTOFT et al., 2008). Existe uma grande possibilidade que o aumento do consumo de FC em CP na Europa continue, tendo em vista a necessidade da redução das emissões de $\mathrm{CO}_{2}$.

Outro ponto favorável à utilização do $\mathrm{FC}$ é sua menor emissão e $\mathrm{CO}_{2}$ relacionada ao transporte, haja vista que a matéria-prima é a mesma do clínquer. Estes e outros aspectos deverão elevar o consumo do FC no CP num futuro próximo, bem como sua 
maior aceitação nas normas técnicas sobre o assunto. Contudo estudos devem ser aprofundados para melhor investigar as características do concreto elaborado com substituição de FC, em especial no que diz respeito à resistência mecânica e durabilidade. Portanto, as sinergias descritas entre CP e FC devem ser totalmente exploradas para maximizar os níveis de substituição.

Estima-se que o limite teórico para a substituição de clínquer no $\mathrm{CP}$ usando combinações de FC e AM tradicionais seja de $40 \%$ antes que o desempenho do concreto seja afetado. Para que isso seja alcançado globalmente, provavelmente 0 nível de substituição por FC precisará ser aumentado em 20\% na média (HERFORT, 2008). Quanto ao FC pode-se dizer que sua utilização em altos teores poderá resultar em uma diminuição acentuada das emissões de $\mathrm{CO}_{2}$ em relação ao uso de energia durante o ciclo de vida dos materiais à base de CP. A adoção de altos teores de FC demandarão investimentos e custos operacionais de menor porte, especialmente quando comparado com os custos previstos para a captura e armazenamento de carbono (CCS).

\section{CONCLUSÃO}

Este trabalho teve por objetivo a elaboração de uma revisão de literatura a respeito da utilização do $\mathrm{FC}$ como substituição parcial do $\mathrm{CP}$ em concretos. Foram verificados teores de substituição que variaram entre $2,4 \%$ e $50 \%$. De modo geral foram reportados diversos aspectos positivos relativos à incorporação do FC no concreto. $\mathrm{A}$ maior, ou menor contribuição do FC no concreto está relacionada, fundamentalmente, ao teor de substituição, ao fator a/ag e a finura.

A finura do FC contribui para o "efeito filer" beneficiando o concreto na redução da demanda por água, na minoração da exsudação e, nos concretos endurecidos, o bloqueio dos poros capilares diminuindo a penetração de agentes agressivos (TSIVILIS, 2010), bem como para a aceleração das reações de hidratação (TAYLOR, 1997). A finura do FC, também, contribui para a diminuição da evaporação e, consequentemente, para a redução da tendência à fissuração plástica o que propicia uma maior resistência à compressão (ESPINING, 2008). 
Quanto à influência dos teores de substituição do $\mathrm{FC}$ e seus reflexos na resistência à compressão do concreto, ainda, não há um consenso entre os autores. Alguns defendem que, para fatores a/ag mais baixos, a resistência à compressão pode ser majorada com teores crescentes de FC (FELTRIN et al., 2016; PALM et al., 2016; SOROKA e SETTER, 1977). Por outro lado, autores como Madani e Ramezanianpour (2016), Zhao et al. (2015) e Dhir et al. (2007) defendem que há uma diminuição da resistência à compressão com o aumento no teor de $\mathrm{FC}$, mesmo para fatores a/ag reduzidos.

Um consenso entre os autores está relacionado ao papel do fator a/ag em concretos com FC incorporado, em especial para teores elevados. Para Palm et al. (2016) e Proske et al. (2013) o fator a/ag é o principal parâmetro para concretos com alto teor de $\mathrm{FC}$, as propriedades mecânicas e de durabilidade dependem quase que exclusivamente dele. Mesmo para concretos elaborados com teores de FC mais baixos o fator a/ag é determinante (RAMEZANIANPOUR; HOOTON, 2014; BONAVETTI et al., 2003; HAWKINS et al., 2003). Neste tema o trabalho de El Barrak et al. (2009) demonstra que, a depender do fator a/ag, o FC possui menos influência na trabalhabilidade e age mais como agente lubrificante.

Foi constatado que a majoração no teor de FC diminui o tempo de início e fim de pega (EL-DIDAMONY et al., 1995), bem como aumenta o calor de hidratação (SCHUTTER, 2011; LOTHENBACH et al., 2008), tendo em vista a aceleração das reações de hidratação devido a maior finura do FC.

Em relação à carbonatação dos concretos com substituição de $\mathrm{CP}$ por FC há posições contraditórias entre os autores. Tsivilis et al. (2003) colocam que a carbonatação não aumenta mesmo com a substituição de $35 \%$ do CP por FC. Por outro lado Lollini et al. (2014) constataram um aumento na carbonatação para um nível de substituição de $30 \%$ do CP por FC e nenhum efeito claro com 15\%. Para teores de substituição mais elevados de FC (45\%), Hooton et al. (2007) concluíram que não ocorreu aumento na carbonatação em relação aos concretos sem FC para um mesmo grau de resistência. 
Quanto à penetração de íons cloretos, observa-se a mesma situação da carbonatação. Hornain et al. (1995) relatam uma diminuição da penetração de íons cloretos devido ao "efeito filer", tendo em vista o aumento da compacidade da matriz cimentícia. Por outro lado Bentz et al. (2009), Ghrici et al. (2007) e Irassar et al. (2001) defendem que há um aumento na penetração de íons cloreto com a substituição de FC em comparação com concretos sem substituição.

Foi constatada a possibilidade da elaboração de concretos com elevados teores de FC (50\%) através da diminuição do fator a/ag (uso de superplastificante de alto desempenho) e da otimização da densidade de empacotamento (PROSKE et al., 2013). Para Palm et al. (2016) concretos com elevados teores de FC podem apresentar propriedades mecânicas e de durabilidade comparáveis aos concretos tradicionais caso seja assegurada uma supervisão rigorosa.

Foram constatados benefícios ambientais com a substituição de CP por FC em concretos. Schmidt et al. (1992) concluíram que a substituição de $15 \%$ em massa do clínquer por $\mathrm{FC}$ reduz as emissões de $\mathrm{CO}_{2}$ em $12 \%$. Resultados similares podem ser obtidos para as emissões de $\mathrm{NO}_{x}$ e $\mathrm{SO}_{2}$.

De modo geral pode-se constatar a viabilidade da elaboração de concretos com a substituição do CP por FC, no entanto, à medida que os teores de FC aumentam há a necessidade de um maior controle na dosagem, principalmente em relação à quantidade de água incorporada na mistura (fator a/ag). Assim, através de boas práticas de projeto e controle de mistura, os concretos elaborados com FC podem ter desempenho semelhante aos concretos sem FC.

Contudo ainda existem controvérsias em relação aos concretos elaborados com FC no que se refere ao comportamento reológico, mecânico e à durabilidade, com resultados discrepantes. Neste sentido devem ocorrer mais pesquisas com o intuito de elucidar os pontos controversos abordando, principalmente, a verificação da durabilidade em longo prazo, incluindo aspectos como carbonatação, difusão de cloreto, resistência à abrasão, reação álcali-sílica e risco de reação química de vários minerais em relação ao $\mathrm{FC}$, bem como o efeito sobre a cinética da corrosão do 
concreto atacado por $\mathrm{CO}_{2}$ e cloreto em vários ambientes relevantes, incluindo ambientes internos secos.

\section{REFERÊNCIAS}

ANTONI, M. Investigation of cement substitution by blends of calcined clays and limestone. 2013. Doctoral Thesis - École Polytechnique Fédérale de Lausanne, Lausane, 2013.

AQEL, M.; PANESAR, D. K. Hydration kinetics and compressive strength of steamcured cement pastes and mortars containing limestone filler. Construction and Building Materials, v. 113, p. 359-368, 2016.

BARBHUIYA, S.; CHOW, P.; MEMON, S. Microstructure, hydration and nanomechanical properties of concrete containing metakaolin. Construction and Building Materials, v. 95, p. 696-702, 2015.

BARKER, A. P.; CORY, H. P. The early hydration of limestone-filled cements blended. In: SWAMY, R. N. Cements in Construction. Essex: Elsevier, 1991, p. 107-124.

BARKER, A. P.; MATTHEWS, J. D. Concrete durability specification by water/cement or compressive strength for European cement types. In: 3 th INTERNATIONAL CONFERENCE ON THE DURABILITY OF CONCRETE, 1994, Detroit. Proceedings [...]. Detroit: ACI SP-145, 1994. p. 1135-1164.

BATTAGIN, A. F.; BATTAGIN, I. L. S. O cimento Portland no Brasil. In: ISAIA, G. C. Materiais de construção civil e princípios de ciência e engenharia de materiais. São Paulo: IBRACON, 2010. p. 761-790.

BENTZ, D. P. Modeling the influence of limestone filler on cement hydration using CEMHYD3D. Cement and Concrete Composites, v. 28, p. 124-129, 2006.

BENTZ, D. P.; IRASSAR, E. F.; BUCHER, B. E.; WEISS, W. J. Limestone fillers conserve cement. Concrete International, v. 31, p. 35-46, 2009. 
BERODIER, E.; SCRIVENER, K. Evolution of pore structure in blended systems. Cement and Concrete Research, v. 73, p. 25-35, 2015.

BERTOLINO, L. C.; PALERMO, N.; BERTOLINO, A. V. F. A. Geologia. In: LUZ, A. B.; ALMEIDA, S. L. M. Manual de agregados para construção civil. Rio de Janeiro: CETEM/MCTI, 2012. p. 69-79.

BONAVETTI, V. L.; DONZA, H.; MENENDEZ, G.; CABRERA, O. Limestone filler cement in low w/c concrete: $A$ rational use of energy. Cement and Concrete Research, n. 33, p. 865-871, 2003.

BONAVETTI, V. L.; RAHHAL, V. F.; IRASSAR, E. F. Studies on the carboaluminate formation in limestone filler-blended cements. Cement and Concrete Research, v. 31, n. 6, p. 853-859, 2001.

COURARD, L.; HERFORT, D.; VILLAGRÁN, Y. Limestone powder. In: DE BELIE, N.; SOUTSOS, M.; GRUYART, E. Properties of fresh and hardened concrete containing supplementary cementitious materials. Paris: RILEM State-of-the-Art Reports, 2018.

DAMINELI, B. L. Conceitos para formulação de concretos com baixo consumo de ligantes: controle reológico, empacotamento e dispersão de partículas. 2013. Tese (Doutorado em Engenharia) - Escola Politécnica da Universidade de São Paulo, São Paulo, 2013.

DAMTOFT, J. S.; LUKASIK, J.; HERFORT, D.; GARTNER, E.; SORRENTINO, D. Sustainable development and climate change initiatives. Cement and Concrete Research, v. 38, p. 115-127, 2008.

DE WEERDT, K. Separate grinding versus intergrinding: State of the art. Trondheim: SINTEF, 2007. 
DHIR, R. K.; LIMBACHIYA, M. C.; McCARTHY, M. J. Evaluation of Portland limestone cements for use in concrete construction. Materials and Structures, v. 40, p. 459473, 2007.

DUAN, P.; SHUI, Z.; CHEN, W.; SHEN, C. Effects of metakaolin, silica fume and slag on pore structure, interfacial transition zone and compressive strength of concrete. Construction and Building Materials, v. 44, p. 1-6, 2013.

EL BARRAK, M.; MOURET, M.; BASCOUL, A. self-compacting concrete paste constituents: Hierarchical classification of their influence on flow properties of the paste. Cement and Concrete Composites, v. 31, p. 12-21, 2009.

EL-DIDAMONY, H.; SALEM, T.; GABR, N.; MOHAMED, T. Limestone as a retarder and filler in limestone blended cement. Ceramics - Silikaty, v. 39, p. 15-19, 1995.

ELGALHUD, A.; DHIR, R.; GHATAORA, G. Chloride ingress in concrete: Limestone addition effect. Magazine of Concrete Research, v. 70, p. 292-313, 2018.

ESPINING, O. Effect of limestone filler BET $\left(\mathrm{H}_{2} \mathrm{O}\right)$ - area on the fresh and hardened properties of self-compacting concrete. Cement and Concrete Research, v. 38, p. 938-944, 2008.

FAGERLUND, G. Imaginable effects of limestone filler on chloride transport (Report TVBM-7187). Lund: Lund University, 2005.

FELTRIN, C. S; ISAIA, G. C.; RUVIARO, E. R.; RODRIGUES, A.; RIBEIRO, L. Empacotamento de partículas com fíler calcário em concretos: Um estudo das propriedades e sustentabilidade. In: $58^{\circ}$ CONGRESSO BRASILEIRO DO CONCRETO, 2016, Belo Horizonte. Anais [...]. São Paulo: IBRACON, 2016.

FENNIS, S. A.; WALRAVEN, J. C. Using particle packing technology for sustainable concrete mixture design. Heron, v. 57, p. 73-101, 2012. 
GHRICI, M.; KATSIOTI, S.; SAID-MANSOUR, M. Mechanical properties and durability of mortar and concrete containing natural pozzolana and limestone blended cement. Cement and Concrete Composites, v. 29, p. 542-549, 2009.

GUEMMADI, Z.; ESCADEILlAS, G.; HOUARI, H.; CLASTRES, P.; TOUMI, B. Influence of limestone fillers on the mechanical performances of cement pastes. In: INTERNATIONAL CONFERENCE CEMENT COMBINATIONS FOR DURABLE CONCRETE, 2005, Dunde. Proceedings [...]. Dundee: University of Dundee, 2005. p. 339-350.

HAWKINS, P.; TENNIS, P. D.; DETWILER, R. J. The use of limestone in Portland cement: A state of the art review. Skokie: Portland Cement Association, 2003.

HEMALATHA, M. S.; SANTHANAM, M. Characterizing supplementary cementing materials in blend mortars. Construction and Building Materials, v.191, p. 440-459, 2018.

HERFORT, D. Developments needed in the production and use of cement for large reductions in $\mathrm{CO}_{2}$ emissions by 2050. In: ANNA MARIA WORKSHOP IX SUSTAINABLE CEMENTS: CHALLENGES, OPPORTUNITIES \& APPLICATIONS, 2008, Holmes Beach. Proceedings [...]. Holmes Beach, 2008.

HOOTON, R. D.; NOKKEN, M.; THOMAS, M. D. A. Portland-limestone cement: state of the art report and gap analysis for CSA A 3000. Mount-Royal: St. Lawrence Cement, 2007.

HORNAIN, H.; MARCHAND, J.; DUHOT, V.; REGOURD, M. Diffusion of chloride ions in limestone filler. Cement and Concrete Research, v. 25, p.1667-1678, 1995.

IEA. Cement technology roadmap: Carbon emissions reductions up to 2050. Paris: OECD Publishing, 2009. Disponível em: <http://www.oecdilibrary.org/energy/cement- technology-roadmap-carbon774emissions-reductions-upto-2050_9789264088061-en>. Acesso em: 02 ago. 2020. 
IPAVEC, A.; GABROVSEK, R.; VULK, T.; KAUCIC, V. Carboaluminate phases formation during the hydration of calcite-containing Portland cement. Journal of the American Ceramic Society, v. 94, p. 1238-1242, 2011.

IRASSAR, E. F. Sulfate attack on cementitious materials containing limestone filler - A review. Cement and Concrete Research, v. 39, p. 241-254, 2009.

IRASSAR, E. F.; BONAVETTI, V. F.; MENENDÉZ, G.; DONZA, H.; CABRERA, O. Mechanical properties and durability of concrete made with Portland limestone cement. In: MALHOTRA, V. M. INTERNATIONAL SYPOSIUM ON THE SUSTAINABLE DEVELOPMENT AND CONCRETE TECHNOLOGY, 2001, Farmington Hills. Proceedings [...]. Farmington Hills: ACI Special Publication, 2001. p. 431-450.

IRASSAR, E. F.; BONAVETTI, V. L.; MENENDEZ, G. Hidratación y propiedades de cemento ternarios con filler calcáreo y escoria. Revista ALCONPAT, v. 5, p. 84-96, 2015.

JOHN, V. M.; DAMINELI, B. L.; QUATTRONE, M. Fillers in cementitious materials: Experience, recent advances and future potential. Cement and Concrete Research, v. 114, p. 65-78, 2018.

KADRI, E. H.; DUVAL, R. Effect of ultrafine particles on heat of hydration of cement mortars. ACI Materials Journal, v. 99, p. 138-142, 2002.

KLIEGER, P.; HOOTON, R. Carbonate additions to cement. West Conshohocken: ASTM, 1990.

KRISHNAN, S.; KANAUJLA, S.; BISHNOI, S. Hydration kinetics and mechanisms of carbonates from stone wastes in ternary blends with calcined clay. Construction and Building Materials, v. 164, p. 265-274, 2018.

KUMAR, A.; OEY, T.; KIM, S.; THOMAS, D.; BADRAN, S. Simple methods to estimate the influence of limestone fillers on reaction and property evolution in cementitious materials. Cement and Concrete Composites, v. 42, p. 20-29, 2013. 
LAWRENCE, P.; CYR, M.; RINGOT, E. Mineral admixtures in mortars effect of type, amount and fineness of fine constituents on compressive strength. Cement and Concrete Research, v. 35, p. 1092-1105, 2005.

LAWRENCE, P.; CYR, M.; RINGOT, E. Mineral admixtures in mortars: Effect of inert materials on short-term hydration. Cement and Concrete Research, v. 33, p. 19391947, 2003.

LIVESEY, P. Performances of limestone-filled cements. In: SWAMY, R. N. Blended cements in construction. London: Elsevier; 1991. p. 1-15.

LOLLINI, F.; REDAELI, E.; BERTOLINI, L. Effects of Portland cement replacement with limestone on the properties of hardened concrete. Cement and Concrete Composites, v. 46, p. 32-40, 2014.

LOTHENBACH, B.; LE SAOUT, G.; GALLUCCI, E. Influence of limestone on the hydration of Portland cements. Cement and Concrete Research, v. 38, p. 848-860, 2008.

MADANI, H.; RAMEZANIANPOUR, A. A. The influence of ultrafine filler materials on mechanical and durability characteristics of concrete. Civil Engineering Infrastructures Journal, v.49, p. 251-262, 2016.

MATSCHEI, T.; LOTHENBACH, B.; GLASSER, F. P. The role of calcium carbonate on cement hydration. Cement and Concrete Research, v. 37, p. 551-558, 2007.

MATTHEWS, J. D. Performance of limestone filler cement concrete. In: DHIR, R. K.; JONES, M. R. Euro-cements - impact of ENV 197 on concrete construction. London: E\&FN Spon, 1994. p. 113-147.

MAYFIELD, L. Limestone additions to Portland cement - An old controversy revisited. Cemente, Concrete and Aggregates, v. 1, p. 3-8, 1988. 
MEDJIGBODO, G.; ROZIERE, E.; CHARRIER, K.; IZORET, L. Hydration, shrinkage, and durability of ternary binders containing Portland cement, limestone filer and metakaolin. Construction and Building Materials, v. 183, p. 114-126, 2018.

MEHDIPOUR, I.; KUMAR, A.; KHAYAT, K. H. Rheology, hydration, and strength evolution of interground limestone cement containing PCE dispersant and high volume supplementary cementitious materials. Materials \& Desing, v.127, p. 54-56, 2017.

MOIR, G. K.; KELHAN, S. Developments in the manufacture and use of Portland limestone cement. ACI Special Publication, v.172, p. 797-819, 1999.

PALM, S; PROSKE, T.; REZVANI, M.; HAINER, S.; MULLER, C.; GRAUBNER, C. A. Cements with a high limestone content - Mechanical properties, durability and ecological characteristics of the concrete. Construction and Building Materials, v. 119, p. 308-318, 2016.

PROSKE, T.; HAINER, S.; REZVANI, M.; GRAUBNER, C. A. Eco-friendly concretes with reduced water and cement contente - Mix design principles and application in practice. Construction and Building Materials, v. 67, p. 413-421, 2014.

PROSKE, T.; HAINER, S.; REZVANI, M.; GRAUBNER, C. A. Eco-friendly concretes with reduced water and cement contentes - Mix design principles and laboratory tests. Cement and Concrete Research, v. 51, p. 38-46, 2013.

RAMEZANIANPOUR, A. M.; HOOTON, R. D. A study on hydration, compressive strength, and porosity of Portland-limestone cement mixes containing SCMs. Cement and Concrete Composites, v. 51, p. 1-13, 2014.

SAHMARAN, M.; CHRISTIANTO, H. A.; YAMAN, I. O. The effect of chemical admixtures and mineral additives on the properties of self-compacting mortars. Cement and concrete composites, v. 28, p. 432-440, 2006.

SCHMIDT, M. Cement with interground additives - Capability and environmental relief. Zement-Kalk-Gips, v. 45, p. 64-69, 1992. 
SCHUTTER, G. Effect of limestine filler as mineral addition in self-compacting concrete. In: 36 th CONFERENCE ON OUR WORLD IN CONCRETE \& STRUCTURES, 2011, Singapore. Proceedings [...]. Ghent: Ghent University, 2011. p. 49-54.

SCRIVENER, K. L.; LOTHENBACH, B.; DE BELIE, N. TC 238-SCM: Hydration and microstructure of concrete with SCMs. Materials and Structures, v. 48, p. 835-862, 2015.

SOROKA, I.; SETTER, N. The effect of fillers on strength of cement mortars. Cement and Concrete Research, v. 7, p. 449-456, 1977.

STARK, J. Optimierte bindemittelsysteme für die betonindustrie. Beton, v. 54, p. 486490, 2004.

STARK, J.; FREYBURG, E.; LÖHMER, K. Investigations in to the influence of limestone additions to Portland cement clinker phases on the early phase of hydration. In: DHIR, R. K.; DYER, T. D. Modern concrete materials: Binders, additions and admixtures. Dundee: University of Dundee, 1999.

SUN, H.; HOHL, B.; CAO, Y.; HANDWERKER, C.; RUSHING, T. S.; CUMMINS, T. K.; WEISS, J. Jet mill grinding of Portland cement, limestone, and fly ash: Impact on particle size, hydration rate, and strength. Cement and Concrete Composites, v. 44, p. 41-49, 2013.

TAYLOR, H. F. W. Cement chemistry. London: Thomas Telford Publishing, 1997.

TSIVILIS, S. A study on the chloride diffusion into Portland limestone cement concrete. Materials Science Forum, v. 636, p. 1355-1361, 2010.

TSIVILIS, S.; BATIS, G.; CHANIOTAKIS, E.; GRIGORIADIS, G.; THEODOSSIS, D. Properties and behavior of limestone cement concrete and mortar. Cement and Concrete Research, v. 30, p. 1679-1683, 2000. 
TSIVILIS, S.; CHANIOTAKIS, E.; BADOGIANNIS, E. A study on the parameters affecting the properties of Portland limestone cements. Cement and concrete composites, v. 21, p. 107-116, 1999.

TSIVILIS, S.; CHANIOTAKIS, E.; KAKALI, G.; BATIS, G. An analysis of the properties of Portland limestone cements and concrete. Cement and Concrete Composites, v. 24, p. 371-378, 2002.

TSIVILIS, S.; TSANTILAS, J.; KAKALI, G.; CHANIOTAKIS, E.; SAKELLARIOU, A. The permeability of Portland limestone cement concrete. Cement and Concrete Research, v. 33, p. 1465-1471, 2003.

USGS. Mineral commodity summaries 2020. Reston: USGS, 2020. Disponível em: https://pubs.usgs.gov/periodicals/mcs2020/mcs2020.pdf. Acesso em: 09 ago. 2020.

VERNET, C. P.; NOWORYTA G. Mechanisms of limestone fillers reactions in the system $\left\{\mathrm{C}_{3} \mathrm{~A}-\mathrm{CSH}_{2}-\mathrm{CH}-\mathrm{CC}-\mathrm{H}\right\}$ : Competition between calcium monocarbo - and monosulfo-aluminate hydrates formation. In: 9 th INTERNATIONAL CONGRESS ON THE CHEMISTRY OF CEMENT, 1992, New Delhi. Proceedings [...]. Ballabgarh: National Council for Cement and Building Materials, 1992. p. 430-436.

VUK, T.; TINTA, V.; GABROVSEK, R.; KAUCIC, V. The effects of limestone addition, clinker type and fineness on properties of Portland cement. Cement and Concrete Research, v. 31, p. 135-139, 2001.

WORLDATLAS. What is limestone. St. Laurent: Worldatlas, 2017. Disponível em: https://www.worldatlas.com/articles/ limestone-facts-geology-of-the-world.html. Acesso em: 03 ago. 2020.

ZHAO, H.; SUN, W.; WU, X.; GAO, B. The properties of the self-compacting concrete with fly ash and ground granulated blast furnace slag mineral admixtures. Journal of Cleaner Production, v. 95, p.66-74, 2015. 
Enviado: Agosto, 2020.

Aprovado: Dezembro, 2020. 